\title{
Isotopic Evidence for Sources of Dissolved Carbon and the Role of Organic Matter Respiration in the Fraser River Basin, Canada
}

Britta M. Voss ( $\sim$ brittamv@gmail.com )

Washington State Department of Ecology https://orcid.org/0000-0003-0149-8106

Timothy I. Eglinton

Eidgenössische Technische Hochschule Zürich: Eidgenossische Technische Hochschule Zurich

Bernhard Peucker-Ehrenbrink

Woods Hole Oceanographic Institution

Valier Galy

Woods Hole Oceanographic Institution

Susan Q. Lang

University of South Carolina

Cameron Mclntyre

Scottish Universities Environmental Research Centre

Robert G. M. Spencer

Florida State University

Ekaterina Bulygina

Old Dominion University

Zhaohui Aleck Wang

Woods Hole Oceanographic Institution

Katherine A. Guay

Bowdoin College

\section{Research Article}

Keywords: river, carbon isotopes, radiocarbon, weathering, carbon cycle

Posted Date: January 5th, 2022

DOI: https://doi.org/10.21203/rs.3.rs-1189548/v1

License: (1) (1) This work is licensed under a Creative Commons Attribution 4.0 International License.

Read Full License 


\title{
Isotopic evidence for sources of dissolved carbon and
} the role of organic matter respiration in the Fraser River basin, Canada

\author{
Britta M. Voss ${ }^{\mathrm{a}, \mathrm{b} * \dagger}$ \\ Timothy I. Eglinton ${ }^{\mathrm{c}}$ \\ Bernhard Peucker-Ehrenbrink ${ }^{\mathrm{a}, \mathrm{d}}$ \\ Valier Galy ${ }^{\mathrm{a}}$ \\ Susan Q. Lang \\ Cameron McIntyre ${ }^{\mathrm{c} *}$ \\ Robert G. M. Spencer ${ }^{\mathrm{f}, \mathrm{g}}$ \\ Ekaterina Bulygina ${ }^{\mathrm{g} !+}$ \\ Zhaohui Aleck Wang ${ }^{\mathrm{a}}$ \\ Katherine A. Guay ${ }^{\mathrm{a} i}$ \\ ${ }^{a}$ Woods Hole Oceanographic Institution, 360 Woods Hole Road, Woods Hole, MA 02543, USA \\ ${ }^{b}$ Massachusetts Institute of Technology, 77 Massachusetts Avenue, Cambridge, MA 02139, \\ USA \\ ${ }^{c}$ Eidgenössische Technische Hochschule, Sonneggstrasse 5, 8092 Zürich, Switzerland \\ ${ }^{\mathrm{d}}$ University of the Fraser Valley, 33844 King Road, Abbotsford, BC V2S 7M7, Canada \\ ${ }^{\mathrm{e}}$ University of South Carolina, 701 Sumter St., Columbia, SC 29208 USA \\ ${ }^{\mathrm{f}}$ Florida State University, 600 West College Avenue, Tallahassee, FL 32306, USA \\ ${ }^{\mathrm{g}}$ Woodwell Climate Research Center, 149 Woods Hole Road, Falmouth, MA 02540, USA \\ *Corresponding author: brittamv@gmail.com \\ ${ }^{\dagger}$ Current address: Washington Department of Ecology, 300 Desmond Dr, Lacey, WA 98503, \\ USA \\ Current address: Scottish Universities Environmental Research Centre, Glasgow G750QF, UK \\ -Current address: Old Dominion University Research Foundation, 4600 Elkhorn Ave, Norfolk, \\ VA 23529, USA \\ Current address: Bowdoin College, 6800 College Station, Brunswick, ME 04011, USA
}

\section{Acknowledgements}

This work was supported by the WHOI Academic Programs Office, the MIT EAPS Department Student Assistance Fund, and the PAOC Houghton Fund to BMV, NSF-ETBC grants OCE0851015 to BPE, VG, and TIE, and OCE-0851101 to RGMS, NSF grant EAR-1226818 to BPE, 

NSF grant OCE-0928582 to TIE and VG, and a WHOI Arctic Research Initiative grant to ZAW.

39 We thank Katherine Kirsch, Sarah Rosengard, Steven Marsh, Sharon Gillies, and numerous

40 students of the University of the Fraser Valley for assistance in the field, and the staff of

41 NOSAMS and the ETH-Zürich Laboratory for Ion Beam Physics for analytical support with

42 radiocarbon measurements. We thank Hannah Gies at ETH-Zürich for preparing the figure

43 containing data from Marwick et al. (2015).

44

\section{$45 \quad$ Keywords}

46 river, carbon isotopes, radiocarbon, weathering, carbon cycle

47 
Abstract

Sources of dissolved and particulate carbon to the Fraser River system vary significantly

50 in space and time. Tributaries in the northern interior of the basin consistently deliver higher

51 concentrations of dissolved organic carbon (DOC) to the main stem than other tributaries. Based

52 on samples collected near the Fraser River mouth throughout 2013, the radiocarbon age of DOC

53 exported from the Fraser River does not change significantly across seasons despite a spike in

54 DOC concentration during the freshet, suggesting modulation of heterogeneous upstream signals

55 during transit through the river basin. Dissolved inorganic carbon (DIC) concentrations are

56 highest in the Rocky Mountain headwater region where carbonate weathering is evident, but also

57 in tributaries with high DOC concentrations, suggesting that DOC respiration may be responsible

58 for a significant portion of DIC in this basin. Using an isotope and major ion mass balance

59 approach to constrain the contributions of carbonate and silicate weathering and DOC

60 respiration, we estimate that up to $29 \%$ of DIC is derived from DOC respiration in some parts of

61 the Fraser River basin. Overall, these results indicate close coupling between the cycling of DOC

62 and DIC, and that carbon is actively processed and transformed during transport through the

63 river network.

64 


\section{Introduction}

Rivers convey large quantities of dissolved organic carbon (DOC) and dissolved inorganic carbon (DIC) from terrestrial environments to the coastal ocean, with the global export flux of DOC from rivers ( 0.25 Gt C a $\mathrm{a}^{-1}$; Hedges et al. 1997; Cai 2011) sufficient to compensate for the estimated annual loss of global marine DOC (Eglinton and Repeta 2014). DOC carried by rivers undergoes rapid biological and abiotic processing within terrestrial watersheds, with the majority subject to remineralization before it reaches the ocean (Catalán et al. 2016). The typically supersaturated state of dissolved $\mathrm{CO}_{2}$ in rivers is at least partially a consequence of microbial conversion of $\mathrm{OC}$ to $\mathrm{CO}_{2}$, and results in significant outgassing of $\mathrm{CO}_{2}$ from river surfaces (Cole and Caraco 2001; Butman and Raymond 2011; Raymond et al. 2013; Reiman and $\mathrm{Xu}$ 2018). Consequently, lateral fluxes of dissolved carbon are less than would occur if rivers functioned as simple pipes, transferring terrestrial material to the ocean (Raymond et al. 2013; Butman et al. 2016; Schädel et al. 2016).

Quantifying the extent of in-transit degradation of riverine organic matter is critical to assessing the role of watersheds in the consumption versus release of atmospheric $\mathrm{CO}_{2}(\mathrm{Perdue}$ et al. 1976; Cole and Caraco 2001; Battin et al. 2009; Tranvik et al. 2009; Aufdenkampe et al. 2011). However, constraining DOC transport and transformation of riverine organic matter is challenging due to seasonal changes in temperature, hydrology, and biology, which affect both the amount and type of material mobilized in river channels over the course of a year, as well as its turnover and transformation along the aquatic continuum. Furthermore, different portions of river basins - potentially draining watersheds containing different vegetation types, soil characteristics, and bedrock lithologies - may produce DOC and DIC in varying quantities and with different organic matter (OM) composition and lability. In situ primary and secondary 
productivity within rivers represent additional sources (and sinks) of DOC and DIC. Identifying geochemical indicators of riverine OC provenance and lability may help elucidate the links between watershed characteristics and ecological behavior, and aid in extending conclusions drawn from process studies of $\mathrm{CO}_{2}$ efflux rates on small spatial scales to larger watersheds. The present study aims to link spatial and temporal variations in the isotopic characteristics of DOC and DIC on the scale of a river basin in order to develop a holistic perspective of source materials and processes of $\mathrm{OM}$ alteration during riverine transport. We focus on dissolved as opposed to particulate carbon phases, because of the $\sim 3 \mathrm{x}$ greater flux of the former (Voss et al. 2015), while acknowledging the potential for interaction and exchange between phases. The study area, the Fraser River basin in southwestern Canada (Fig. 1), provides a unique setting for such a study due to two main features: $(i)$ its modest size $\left(\sim 232,000 \mathrm{~km}^{2}\right)$ and accessibility allows for a detailed characterization of the majority of its tributary basins, while (ii) its variety of bedrock lithology (including carbonate outcrops in certain tributary basins) and spatial and temporal precipitation gradients impart naturally large variability in biogeoclimatic zones, and water geochemistry (Voss et al. 2014), and thus, potentially, gradients in carbon isotopes.

Previous work on the impact of bedrock diversity and seasonal hydrology on dissolved and particulate inorganic constituents in the Fraser basin (Cameron et al. 1995; Cameron 1996; Cameron and Hattori 1997; Voss et al. 2014, 2015) has documented the importance of detailed basin-wide characterizations of source compositions and seasonal sampling to understand the provenance and variability of material reaching the river mouth in this heterogeneous system. This study now extends this approach to basin-scale carbon dynamics. The use of bulk concentrations and isotope compositions allows for the quantification of the relative influence of 
111 chemical weathering and biological processing on the geochemical composition of dissolved

112 carbon pools exported by the Fraser River.

\section{2. Methods}

115

\subsection{DIC and DOC concentrations}

Samples for DIC were collected by pumping water in-line over membrane filters $(0.45$ $\mu \mathrm{m}$ pore size used for 2009 and 2010 samples; $0.2 \mu \mathrm{m}$ pore size for 2011 samples) into precleaned (with mild Liquinox soap solution and rinsed thoroughly with purified water) $250 \mathrm{~mL}$ borosilicate glass bottles with ground glass stoppers. Bottles were overfilled with $3 x$ the sample volume and poisoned immediately with $60 \mu \mathrm{L}$ saturated $\mathrm{HgCl}_{2}$ solution. Glass stoppers were sealed with vacuum grease (Apiezon $M$ ) and secured with rubber bands. DIC concentration was measured on a DIC analyzer (Apollo SciTech LLC., Model AS-C3) at Woods Hole

Oceanographic Institution (WHOI). The measurements are based on acidification of water samples (by $10 \% \mathrm{H}_{3} \mathrm{PO}_{4}$ ), followed by $\mathrm{N}_{2}$ gas stripping of $\mathrm{CO}_{2}$ in the acidified samples and infrared detection of $\mathrm{CO}_{2}$ by a $\mathrm{LiCOR}^{\circledR} 7000 \mathrm{CO}_{2}$ analyzer (Wang et al. 2017). The DIC analyzer was calibrated by Certified Reference Materials of DIC provided by Dr. A.G. Dickson at the Scripps Institution of Oceanography (Dickson 2010; Sarma et al. 2011).

Samples for DOC concentration measurements were filtered in the same manner as DIC samples and collected in 20-60 mL low-density polyethylene bottles (precleaned with 10\% $\mathrm{HCl}$ ). Samples were acidified with $12 \mathrm{~N} \mathrm{HCl}$ to $\mathrm{pH} 2$ in the field and stored refrigerated until analysis. DOC concentrations were analyzed by high temperature combustion on a Shimadzu TOC analyzer. 


\section{$2.2{ }^{13} \mathrm{C}$ and ${ }^{14} \mathrm{C}$ analyses of DOC and DIC}

Samples for DOC and DIC isotope analyses were filtered in the same manner as those for concentration analysis but collected in different bottles. DOC isotope samples were collected in pre-combusted $\left(450^{\circ} \mathrm{C}, 5\right.$ hours $) 1 \mathrm{~L}$ amber glass bottles and acidified immediately with $\mathrm{H}_{3} \mathrm{PO}_{4}$ (Certified ACS grade) to $\mathrm{pH}$ 2. DIC isotope samples were collected in combusted $\left(450^{\circ} \mathrm{C}, 5\right.$ hours) $500 \mathrm{~mL}$ borosilicate glass bottles, poisoned immediately with $100 \mu \mathrm{L}$ of saturated $\mathrm{HgCl}_{2}$ solution, and sealed with greased (Apiezon M) ground glass stoppers and rubber bands. DIC isotope samples were analyzed at the National Ocean Science Accelerator Mass Spectrometry (NOSAMS) facility in Woods Hole, USA, and DOC isotope samples were analyzed at either NOSAMS or the Laboratory for Ion Beam Physics at the Eidgenössische Technische Hochschule (ETH) in Zürich, Switzerland. DOC isotope samples were analyzed by either UV oxidation (Beaupré et al. 2007) or by wet chemical oxidation, a method which has been shown to be comparable to UV oxidation (Lang et al. 2016). Briefly, for UV oxidation, DOC samples were sparged to remove DIC, then UV-irradiated for 4 hours and sparged on an in-line vacuum line cryo-trap; evolved $\mathrm{CO}_{2}$ was converted to graphite and analyzed for ${ }^{14} \mathrm{C}$ by accelerator mass spectrometry (AMS) at NOSAMS (Roberts et al. 2010); a split of $\mathrm{CO}_{2}$ was collected for ${ }^{13} \mathrm{C}$ analysis by dual-inlet isotope ratio MS (IRMS) (McNichol et al. 2000). For wet chemical oxidation, samples were sparged in Exetainer vials containing potassium persulfate, then heated to $100^{\circ} \mathrm{C}$ to allow quantitative conversion of $\mathrm{DOC}$ to $\mathrm{CO}_{2}$; evolved $\mathrm{CO}_{2}$ was directly sampled from vials and injected onto a gas ion source AMS at ETH for ${ }^{14} \mathrm{C}$ analysis (see Lang et al. 2016, for detailed methodology). DIC samples were sparged, $\mathrm{CO}_{2}$ converted to graphite following collection of a $\mathrm{CO}_{2}$ split for ${ }^{13} \mathrm{C}$ analysis by IRMS, and analyzed for ${ }^{14} \mathrm{C}$ by AMS at NOSAMS. Results have been revised based on the recent NOSAMS ${ }^{14} \mathrm{C}$-DOC procedural blank correction 
157

158

159

160

161

162

163

164

165

166

167

168

169

170

171

172

173

174

175

176

177

178

179

assessment (Xu et al. 2021). Analytical precision for NOSAMS DOC and DIC ${ }^{14} \mathrm{C}$ Fraction modern $(\mathrm{Fm})$ values was better than 0.005 , and for ETH DOC ${ }^{14} \mathrm{C}$ was better than 0.04 .

\section{Results}

\subsection{Dissolved organic and inorganic carbon distribution of the Fraser River}

The dissolved carbon budget of the Fraser River is dominated by DIC. At nearly every site and all times of year, the concentration of DIC is the largest component of total dissolved carbon species (DIC+DOC), constituting $80 \%$ on average (Table 1, Fig. 2A-C). Relatively high concentrations of DIC are found in particular tributaries (Robson, McGregor, Blackwater, Willow, and Bridge rivers), which span a wide swath of the Fraser basin and are not restricted to areas draining particular bedrock lithologies (Wheeler et al. 1991). Tributaries with relatively low DIC concentrations (Harrison and Pitt rivers), however, represent areas dominated by acidic intrusive igneous rocks and minor metamorphic units of the Coast Belt with presumably only finely disseminated carbonate minerals, but no carbonate-rich sedimentary lithologies. DOC exhibits a very different spatial pattern (Fig. 2D-F), with the highest concentrations in tributaries draining the peneplain region upstream of Prince George (Nechako and Willow rivers), and a Coast Range tributary, the Blackwater River, with especially high DOC concentrations (466$1479 \mu \mathrm{mol} \mathrm{L}{ }^{-1}$ ) relative to all other sites under all flow conditions. Another group of tributaries (the Bridge, McGregor, Robson, Pitt, and Harrison rivers) is notable for its relatively low DOC concentration $(<212 \mu \mathrm{mol} \mathrm{L}-1)$.

DIC and DOC fluxes are generally highest under high discharge conditions and lowest during low discharge conditions across tributaries of the Fraser River (Fig. 3). The Thompson River, which contributes the greatest proportion ( 20-25\%) of discharge to the Fraser River of 
all tributaries, also accounts for the largest proportions of DOC and DIC under nearly all discharge conditions. The only exception is that, under medium discharge conditions, the Nechako River DOC flux was the greatest of all tributaries, on account of the relatively high DOC concentrations in the northern peneplain portion of the basin. The eight tributaries shown in Figure 3 account for $45-61 \%$ of the DIC flux, and 51-82\% of the DOC flux, of the Fraser River at Fort Langley near the coast under the three observed flow conditions.

\subsection{Isotopic signatures of DOC and DIC}

The isotope compositions of Fraser basin tributaries and points along the main stem were measured primarily in samples collected during medium discharge conditions in summer 2009 (Fig. 4). The stable carbon isotopic composition of DIC ( $\delta^{13} \mathrm{C}$-DIC) ranged from -8.7 to $-3.8 \%$, with the highest values occurring in tributaries of the central portion of the basin (Quesnel, Chilcotin, and Thompson rivers) and the headwaters (Fraser River at Fitzwilliam and Robson River). Corresponding $\delta^{13} \mathrm{C}$-DOC values spanned a narrower range, from -27.3 to $-26.2 \%$. The $\Delta^{14} \mathrm{C}$-DIC values of main stem sites are relatively invariant across the basin, ranging from -110 to $-145 \%$. In contrast, tributaries of the central portion of the basin (Nechako, Blackwater, Quesnel, Chilcotin, and Thompson rivers) are more variable, with relatively high $\Delta{ }^{14} \mathrm{C}$-DIC (-135 to $-4 \%$; younger ${ }^{14} \mathrm{C}$ age) compared to a lower $\Delta^{14} \mathrm{C}$-DIC value (older ${ }^{14} \mathrm{C}$ age) for the sole site analyzed in the Rocky Mountains (Robson River, -294\%o). The $\Delta^{14}$ C-DOC values of most sites in the Fraser basin are higher than those of DIC, corresponding to near modern or greater-than-modern (i.e., post-bomb) ${ }^{14} \mathrm{C}$ ages. Three sites (Fraser River at Lillooet and Blackwater and Chilcotin rivers) from the high discharge period in 2011 were also analyzed for $\delta^{13} \mathrm{C}$ - and $\Delta^{14} \mathrm{C}$ values of DOC. In the case of $\delta^{13} \mathrm{C}$-DOC, the values for these sites during 
high discharge were 0.6 to $0.9 \%$ lower than those during medium discharge, while there were no consistent differences between high and medium discharge for $\Delta^{14} \mathrm{C}$-DOC values. The $\Delta^{14} \mathrm{C}$ DOC value in the Fraser River at Lillooet was 26\%o lower during medium discharge than during high discharge, whereas the $\Delta^{14} \mathrm{C}-\mathrm{DOC}$ values in the Blackwater and Chilcotin Rivers were $19 \%$ and 59\% higher during medium discharge than during high discharge, respectively.

In 2013, $\Delta{ }^{14} \mathrm{C}$-DOC samples collected near the mouth of the Fraser River over the course of a full year (Fig. $5 \mathrm{~A}$ ) ranged from -106 to $+31 \%$, with a mean of $-13 \pm 39 \%$ ( 1 s.d.). The average measurement uncertainty was $\pm 26 \%$ o (representing the $1 \sigma$ measurement error propagated through the correction for the presence of the processing blank). DOC did not exhibit any clear temporal trends in $\Delta^{14} \mathrm{C}$ values.

\section{Discussion}

\subsection{Flow-dependence and spatial patterns of DOC and DIC}

Concentrations of DIC and DOC in the Fraser River main stem exhibit similar downstream trends. In general, concentrations are relatively low in the Rocky Mountain headwaters, elevated in the central portion of the basin, and gradually decline for roughly the second half of the river's length. The tributary inputs of each of these pools, however, are distinct, contributing to spatial variability and varying in their response to seasonal changes in discharge.

The downstream pattern of tributary DOC concentrations features relatively low concentrations in tributaries draining the Rocky Mountains and the lower Coast Range, and higher concentrations in tributaries draining the central portion of the basin (Cariboo and upper Coast Range). This pattern likely reflects the thin and immature soils in the mountainous headwaters in contrast with the more established soils and low-lying wetland areas of the central 
and lower portion of the basin. The main stem Fraser exhibits a similar spatial pattern, with rising DOC concentrations from the headwaters until Hansard/Stoner ( $500 \mathrm{~km}$ from the river source), followed by a slight decrease as the river enters the relatively arid central basin, which continues for the remainder of its course. While this spatial pattern is consistent between the different flow regimes, the absolute concentrations vary substantially. DOC concentrations are lowest in the samples collected during medium discharge (summer), somewhat higher during low discharge (fall), and highest during the spring freshet. This freshet DOC pulse is a common feature of many high-latitude rivers (Holmes et al. 2008; Cooper et al. 2008; Guo et al. 2012), and results from changing hydrologic flowpaths as surface soils across the basin become inundated (to an average depth of 0.2-0.8 m), releasing DOM accumulated throughout the previous fall and winter (Voss et al. 2015). In the Fraser basin, with the wide variety of biogeoclimatic zones and land cover, the initiation of the spring freshet can vary by a few weeks between individual tributary basins. Therefore, the high discharge samples from spring 2011 likely capture slightly different stages of the freshet DOC pulse in each tributary sub-basin. The seasonal variations in DIC concentrations are notably decoupled from those of DOC, suggesting the influence of additional drivers (other than DOC remineralization). DIC is the single largest component of the dissolved load of the Fraser River and its concentration at most sites varies only modestly between high, medium, and low discharge conditions, suggesting DIC fluxes are primarily driven by the amount of discharge (Fig. 5). In contrast, the variability in DOC concentrations across different discharge conditions supports the assertion that the sources of DOC change in nature throughout the year (Voss et al. 2015). 


\subsection{Sources of DOC}

The relatively ${ }^{14} \mathrm{C}$-depleted values of DOC in headwater areas of the Fraser basin indicate the mobilization of aged organic material. The latter may derive from soil, bedrock, and/or anthropogenic sources (i.e., products of fossil fuel utilization). Combustion-derived aerosols are a significant source of ancient OC in surface waters and soils globally (Jaffé et al. 2013). In the lower Fraser River downstream of the major tributaries, black carbon, with a $\Delta^{14} \mathrm{C}$ value of $570 \%$, constitutes $6.9 \pm 0.5 \%$ of the POC pool (Coppola et al. 2018), and on a global basis dissolved black carbon is estimated to account for $\sim 10 \%$ of the global riverine flux of DOC (Jaffé et al. 2013). DOC in streams draining coastal and mountainous glaciers of western North America in particular have been shown to contain a significant aged component, most likely from aerosols derived from fossil fuel combustion (Hood et al. 2009; Stubbins et al. 2012), and there is evidence of combustion-derived OM in the Fraser basin dating back to the early Holocene (Hallett et al. 2003). Though less directly impacted by air masses originating from east Asia (the predominant source for aerosols to the North American west coast), some fossil fuel combustion-derived aerosols may be deposited on mountain glaciers of the Fraser basin. However, if this is the case, it is not clear why relatively old DOC would be restricted only to these headwater basins, given that most major tributaries of the Fraser River have headwaters fed by glaciers (Thorne and Woo 2011). It may be that glacial-derived DOC is relatively bio-labile and is rapidly degraded, as has been observed in other streams and rivers (Hood et al. 2009; Hemingway et al. 2019), leaving little ${ }^{14} \mathrm{C}$ evidence in downstream DOC samples. The importance of glacial influence may be obscured by differences in residence time between tributaries given that the tributaries carrying relatively aged DOC are smaller than most of the others analyzed. It is currently not possible to exclude contributions of fossil combustion 
271 residues to the ${ }^{14} \mathrm{C}$-depleted DOC signals given current uncertainties concerning the reactivity of 272 dissolved combustion-derived components (Stubbins et al. 2012; Wagner et al. 2021), but the 273 lack of coherence in values across tributaries suggests that aged DOC in the Fraser system is 274 driven by processes other than deposition of anthropogenic combustion-derived aerosols on 275 glaciers. Instead, we speculate that ${ }^{14} \mathrm{C}$-depleted DOC in the Fraser River and its tributaries is 276 primarily derived from mobilization and dissolution of pyrogenic fossil carbon and pre-aged 277 biogenic OM in soils and glacial debris. Further information on DOM composition and dynamics 278 is needed to fully address the question of DOC provenance in the Fraser basin. As a test of the above hypothesis that DOC respiration is an important source of DIC in the Fraser River, it might be expected that DIC $\delta^{13} \mathrm{C}$ values would reflect isotopic signatures 281 associated with DOC consumption. DIC derived from respiration of $\mathrm{C}_{3}$ plant material (with a $282 \quad \delta^{13} \mathrm{C}$ value of $\sim-27 \%$ o) would be expected to have a $\delta^{13} \mathrm{C}$ value of $\sim-18 \%$ (Clark and Fritz 1997), 283 while DIC derived from weathering of carbonate or silicate rocks would be expected to have $284 \delta^{13} \mathrm{C}$ values of approximately $-8.25 \%$ and $-17 \%$, respectively (Spence and Telmer 2005). In situ 285 production may also influence $\delta^{13} \mathrm{C}$ values, resulting in a residual DIC pool with higher $\delta^{13} \mathrm{C}$ 286 values. The $\delta^{13} \mathrm{C}$ values of DIC (-3.8 to $-8.7 \%$ ) and DOC (-26.2 to $-27.3 \%$ ) in the Fraser River 287 likely reflect the interplay of leaching and respiration of $\mathrm{C}_{3}$ plant material and mineral 288 weathering and possibly aquatic autotrophic biomass (although the Fraser basin is on the whole 289 heterotrophic; Raymond et al. 2013). The data from this study cannot fully disentangle the 290 impact of these sources on bulk DIC and DOC $\delta^{13} \mathrm{C}$ values. Future studies which specifically 291 investigate the magnitude and spatial and temporal variation of autotrophic production in the 292 Fraser River and the distribution of carbonate-bearing soils would shed light on the relative 
importance of these sources as an independent comparison with the contribution of respired DOC to the DIC pool estimated here.

\subsection{Weathering and respiration controls on load and composition of DIC and DOC}

The inorganic geochemical composition of dissolved material provides multiple indicators of the influence of carbonate weathering in certain portions of the Fraser basin (Voss et al. 2014). The relatively high DIC concentrations in certain tributaries also suggest a contribution from carbonate-rich lithologies; however, other weathering reactions also produce DIC (Blattmann et al. 2019; Hilton and West 2020), while biological consumption or production of DIC may also affect riverine DIC loads (Voss et al. 2017). The dissolved inorganic load of the Fraser River (excluding carbonate species) is essentially a binary mixture of carbonate- and silicate-derived weathering products (Voss et al. 2014), although sulfide weathering also occurs in certain regions (Cameron et al. 1995; Spence and Telmer 2005). The major cation composition $(\mathrm{Ca} / \mathrm{Na}$ and $\mathrm{Mg} / \mathrm{Na})$ of the Robson River in particular resembles that of runoff from carbonatedominated lithologies (Meybeck 1986; Gaillardet et al. 1999), and therefore its composition likely reflects major element contributions due almost entirely to carbonate weathering. Sites in other parts of the basin, however, reflect a more complex combination of biogeochemical processes impacting the dissolved load.

To quantify the importance of carbonate weathering, silicate weathering, and OM respiration to the DIC load of the Fraser, we used the concentrations of dissolved major elements, DIC, and DOC, and corresponding carbon isotopic compositions, in a series of mass balance relationships. We applied these calculations to the 8 sites from the medium discharge sampling campaign in 2009 for which we have complete concentration and isotopic composition 
data (i.e., the main stem Fraser River at Fitzwilliam, Stoner, and Vancouver shallow; and tributaries Nechako, Blackwater, Quesnel, Chilcotin, and Thompson rivers). First, carbonate- and non-carbonate-derived DIC fractions are constrained by their ${ }^{13} \mathrm{C}$ and ${ }^{14} \mathrm{C}$ values:

$f_{\text {carb }}+f_{N C}=1$

$f_{\text {carb }} \delta_{\text {carb }}+f_{N C} \delta_{N C}=\delta_{\text {meas }}$

$f_{\text {carb }} \Delta_{\text {carb }}+f_{N C} \Delta_{N C}=\Delta_{\text {meas }}$

where $\delta$ and $\Delta$ represent the stable and radiocarbon isotope compositions, respectively, of DIC from carbonate weathering ( $c a r b)$, non-carbonate-weathering processes $(N C)$, and measured samples (meas). The proportions of carbonate-weathering-derived DIC $\left(f_{c a r b}\right)$ and non-carbonateweathering-derived DIC $\left(f_{N C}\right)$ can be approximated from dissolved major ion composition, after correction for sea salt aerosols. As dissolved chloride is almost entirely derived from sea salt aerosols in the Fraser River (Voss et al. 2014), we correct other major ion concentrations as follows:

$[X]_{\text {nss }}=[X]_{\text {meas }}-[C l]_{\text {meas }}\left(\frac{X}{\text { cl }}\right)_{\text {ss }}$

where $X$ is any major ion, $n s s$ indicates non-sea-salt-derived, and $s s$ is sea-salt-derived. The Robson River, with major ion ratios very similar to a pure carbonate weathering endmember (Gaillardet et al. 1999), is used to estimate the non-carbonate-weathering-derived fraction of DIC in other sites as follows:

$f_{N C}=\frac{[D I C]_{N C}}{[D I C]_{\text {meas }}}=\frac{1}{[D I C]_{\text {meas }}}\left[D I C_{\text {meas }}-\left(\frac{C a+M g}{N a}\right)_{n s s} \times\left(\frac{D I C}{(C a+M g) / N a}\right)_{\text {Robson }}\right]$

The sea salt aerosol correction is complicated for the Robson River medium discharge sample as the dissolved $\mathrm{Cl}$ value of $43 \mu \mathrm{mol} \mathrm{L}{ }^{-1}$ reported by Voss et al. (2014) is relatively high compared to corresponding values at low and high discharge (4.6 and $5.7 \mu \mathrm{mol} \mathrm{L}^{-1}$, respectively), suggesting that it is likely influenced by sources other than atmospheric aerosols. $\mathrm{Cl}$ 
concentrations for other Rocky Mountain tributaries, i.e. McGregor, Holmes, and Small rivers, under all discharge conditions do not exceed $5.5 \mu \mathrm{mol} \mathrm{L}{ }^{-1}$, and all other Fraser basin samples under medium discharge conditions do not exceed $18.5 \mu \mathrm{mol} \mathrm{L} \mathrm{L}^{-1}$. We therefore chose to correct the sea salt contribution to the medium discharge Robson River sample using a Cl concentration of $3 \mu \mathrm{mol} \mathrm{L}{ }^{-1}$, which represents the lower range of $\mathrm{Cl}$ concentrations for Rocky Mountain tributaries during this sampling time, and therefore yields a lower-limit estimate of noncarbonate DIC in other Fraser basin samples. The choice of $\mathrm{Cl}$ concentration estimate for this sample is clearly important; however, within reasonable bounds, the exact value does not substantially alter the result and interpretation of the estimate of non-carbonate DIC.

The isotope compositions of DIC derived from carbonate weathering contains signatures from both carbonic acid weathering and sulfuric acid weathering of carbonate minerals. The impact of sulfuric acid weathering can be estimated with a similar mass balance:

$f_{C}+f_{S}=1$

$f_{C} \delta_{C}+f_{S} \delta_{S}=\delta_{c a r b}$

$f_{C} \Delta_{C}+f_{S} \Delta_{S}=\Delta_{c a r b}$

where $C$ and $S$ indicate carbonic acid weathering of carbonates and sulfuric acid weathering of carbonates. Since carbonic acid weathering of carbonates produces one mole of carbon derived from soil $\mathrm{CO}_{2}$ (a mixture of atmospheric $\mathrm{CO}_{2}$ and soil organic matter respiration) and one mole from the carbonate mineral being dissolved, $\delta_{C}$ is the average of the $\delta^{13} \mathrm{C}$ composition of soil $\mathrm{CO}_{2}$ adjusted for the fractionation effect of dissolution (predominantly as $\mathrm{HCO}_{3}{ }^{-}$at typical Fraser River $\mathrm{pH}$ ), or -17\%o, and mineral $\mathrm{CaCO}_{3}, \sim 0 \%$, i.e., $\sim-8.25 \%$ (Spence and Telmer 2005). Likewise, $\Delta_{C}$ is the average $\Delta^{14} \mathrm{C}$ of modern atmospheric $\mathrm{CO}_{2}$ at the time of sampling $(\sim 48 \%$ o and mineral $\mathrm{CaCO}_{3}(-1000 \%$, assuming any secondary soil carbonate is negligible), or -476\%o. 
Sulfuric acid weathering of carbonates produces DIC derived only from mineral $\mathrm{CaCO}_{3}$, therefore $\delta_{S}=0 \%$ and $\Delta_{S}=-1000 \%$. In principle, the sulfuric acid contribution to carbonate weathering $\left(f_{S}\right)$ can be approximated based on patterns of $\mathrm{SO}_{4}{ }^{2-}$ concentrations and stable sulfur isotope values $\left(\delta^{34} S_{S O_{4}^{2-}}\right)$. Practically, however, this requires careful consideration of a range of endmembers (e.g., evaporites, atmospheric deposition) as well as potential alterations of the $\delta^{34} S_{S_{4}^{2}-}$ values via microbial sulfate reduction along the course of the river (e.g., Calmels et al. 2007; Torres et al. 2016; Hemingway et al. 2020). Yet, the low $\mathrm{SO}_{4}{ }^{2-}$ concentrations and high $\delta^{34} S_{S O_{4}^{2-}}$ values in the Fraser basin reported in the literature (Cameron et al. 1995; Spence and Telmer 2005; Voss et al. 2014; Burke et al. 2018) allow for rough constraints on the relative contribution of sulfuric acid weathering to carbonate weathering. Based on this, we assert that the sulfuric acid contribution to carbonate weathering is relatively minor, and we estimate $f_{S}$ is $\sim 0.08$. We further note that the exact value of $f_{S}$ within reasonable bounds $(\sim 5-30 \%)$ does not significantly impact our isotope mass balance, as will be described later. Using these values, we solve Equations 6-8 for $f_{C}, \delta_{c a r b}$, and $\Delta_{c a r b}$, and subsequently Equations 1-3 can be solved for $\delta_{N C}$ and $\Delta_{N C}$.

Next, we construct a mass balance for non-carbonate-weathering-derived DIC, which is derived from silicate weathering, $\mathrm{OM}$ respiration, and atmospheric $\mathrm{CO}_{2}$ invasion:

$f_{S W O M}+f_{\text {atm }}=1$

$f_{S W O M} \delta_{S W O M}+f_{a t m} \delta_{a t m}=\delta_{N C}$

$f_{S W O M} \Delta_{S W O M}+f_{a t m} \Delta_{a t m}=\Delta_{N C}$

where atm refers to atmospheric $\mathrm{CO}_{2}$ and $S W O M$ to the combination of organic matter respiration and silicate weathering. We group organic matter respiration and silicate weathering together because the isotopic signatures of DIC produced by each of these processes are 
385

386

387

388

389

390

391

392

393

394

395

396

397

398

399

400

401

402

403

404

405

406

practically indistinguishable, and the DIC contribution from silicate weathering is quantified separately below. The values of $\delta_{S W O M}$ and $\delta_{\text {atm }}$ are estimated as the measured $\delta^{13} \mathrm{C}$ values of DOC (as an approximation of soil $\mathrm{CO}_{2}$ composition) and modern atmospheric $\mathrm{CO}_{2}$, respectively, both adjusted for a $\sim 9.6 \%$ fractionation effect due to speciation from $\mathrm{CO}_{2}(g)$ to $\mathrm{HCO}_{3}{ }^{-}(a q)$, which assumes all DIC is $\mathrm{HCO}_{3}{ }^{-}$and an average Fraser River water temperature of $10^{\circ} \mathrm{C}$.

Similarly, the values of $\Delta_{S W O M}$ and $\Delta_{\text {atm }}$ are estimated as the measured $\Delta^{14} \mathrm{C}$ values of DOC and modern atmospheric $\mathrm{CO}_{2}$, respectively. Based on these values, Equations 9-11 can be solved for $f_{S W O M}$ and $f_{\text {atm }}$

Next, we construct a mass balance for DIC, composed of contributions from carbonate weathering, atmospheric $\mathrm{CO}_{2}$ invasion, and $\mathrm{OM}$ respiration + silicate weathering:

$f_{\text {carb }}+f_{\text {atm }} f_{N C}+f_{\text {SWOM }} f_{N C}=1$

$[D I C]=f_{\text {carb }}[D I C]+f_{\text {atm }} f_{N C}[D I C]+f_{S W O M} f_{N C}[D I C]$

and a second mass balance to isolate the silicate-weathering-derived portion of $f_{S W O M}$ :

$f_{S W O M} f_{N C}[D I C]=[D I C]_{\text {sil }}+[D I C]_{D O C}=[D I C]\left(f_{\text {sil }}+f_{D O C}\right)$

where $f_{\text {sil }}$ is the portion of DIC produced by silicate weathering and $f_{D O C}$ is the portion produced by OM respiration, which is assumed to be entirely derived from DOC, either in soil pore waters, groundwater or in the river. By doing so, we implicitly neglect contributions from respiration of old soil organic carbon and weathering of petrogenic carbon. The former is consistent with observations that soil organic carbon respiration is dominated by young organic carbon from the soil organic horizon (Trumbore 2000). The latter is likely reasonable considering the low petrogenic $\mathrm{C}$ concentrations in most bedrocks in the Fraser River catchment as well as in Fraser River suspended sediments (Voss et al. 2014; Galy et al. 2015). The silicate weathering 
407 contribution can be estimated based on the major ion composition of each site in comparison to 408 carbonate and silicate end-members as follows:

$409 \quad f_{\text {sil }}=\frac{(\mathrm{Ca} / \mathrm{Na})_{\text {meas }}-(\mathrm{Ca} / \mathrm{Na})_{c a r b}}{(\mathrm{Ca} / \mathrm{Na})_{\text {sil }}-(\mathrm{Ca} / \mathrm{Na})_{\text {carb }}}$

410 where $(\mathrm{Ca} / \mathrm{Na})_{\text {carb }}$ and $(\mathrm{Ca} / \mathrm{Na})_{\text {sil }}$ represent the molar $\mathrm{Ca} / \mathrm{Na}$ composition of carbonate and

411 silicate weathering end-members. Based on long-term correlations of molar $\mathrm{Mg} / \mathrm{Na}$ vs $\mathrm{Ca} / \mathrm{Na}$ in

412 the main stem Fraser River we applied the silicate end-member composition of 0.2 which is at

413 the low end of the range defined by Gaillardet et al. (1999); however, we used the Robson River

414 composition for the carbonate end-member $(\mathrm{Ca} / \mathrm{Na}=75$, rather than 50 as suggested by

415 Gaillardet et al. 1999) to better match the lithology of the Fraser basin. These values are also

416 comparable to carbonate and silicate weathering $\mathrm{Ca} / \mathrm{Na}$ end-member compositions reported by

417 Négrel et al. (1993) of $60 \pm 30$ and $0.35 \pm 0.25$, respectively. The silicate- and non-silicate-

418 weathering-derived portions of each major element can then be calculated as follows, applying

$419 \mathrm{Ca} / \mathrm{Na}$ (as defined above) and $\mathrm{HCO}_{3} / \mathrm{Na}$ end-member compositions from Gaillardet et al. (1999):

$420 \quad[\mathrm{Na}]_{\text {sil }}=f_{\text {sil }}[\mathrm{Na}]_{n s s}$

$421 \quad[N a]_{n o n-s i l}=[N a]_{n s s}-[N a]_{\text {sil }}$

$422[\mathrm{Ca}]_{\text {non-sil }}=[\mathrm{Na}]_{\text {non-sil }} \times\left(\frac{\mathrm{Ca}}{\mathrm{Na}}\right)_{\text {carb }}$

$423 \quad[\mathrm{Ca}]_{\text {sil }}=[\mathrm{Ca}]_{\text {nss }}-[\mathrm{Ca}]_{\text {non-sil }}$

$424 \quad\left[\mathrm{HCO}_{3}\right]_{s i l}=[\mathrm{Na}]_{\text {sil }} \times\left(\frac{\mathrm{HCO}_{3}}{\mathrm{Na}}\right)_{\text {sil }}$

425 Assuming that $\left[\mathrm{HCO}_{3}\right]_{\text {sil }}$ is equivalent to $[\mathrm{DIC}]_{\text {sil }}$, this quantity can be used in Equation 14 to 426 solve for $[D I C]_{D O C}$, the portion of DIC directly derived from OM respiration, either in soil pore 427 waters, groundwaters, or during river transit. Based on this calculation, we estimate that DOC 428 respiration can contribute up to $29 \%$ of the DIC load at some locations in the Fraser River (Table 
4). Certain sites have a very low proportion of DOC respiration-derived DIC, such as the Fraser

430 at Fitzwilliam in the Rocky Mountain headwaters (1\%) and the Chilcotin River in the dry central

431 basin (4\%). The proportion of DOC respiration-derived DIC correlates strongly with DOC

432 concentration $\left(r^{2}=0.58\right.$; Fig. 6$)$, which provides support for this approach to estimating the

433 significance of DOC respiration.

434 The assumption that carbonate and silicate weathering, DOC respiration, and atmospheric

$435 \mathrm{CO}_{2}$ invasion are the sole sources of DIC is imperfect. For instance, potential DIC contributions

436 from sulfuric acid carbonate weathering are not fully characterized by our data. Additionally, we

437 neglected losses from mineral precipitation, $\mathrm{CO}_{2}$ efflux, abiotic DOC mineralization (i.e., photo-

438 oxidation), or in situ autotrophic uptake, and their associated stable isotope fractionations.

439 Nevertheless, the strong correlation between DOC-respiration-derived DIC and DOC

440 concentration clearly points to DOC as an important source of DIC in this fluvial system. We

441 also emphasize that our estimates are based on a single sampling campaign. Given the significant

442 seasonal variability in DOC concentrations in the Fraser River, the DIC contribution from DOC

443 respiration likely also varies seasonally. As our study relies on samples collected along the main

444 steam and near the outlets of major tributaries, we also cannot decipher whether the majority of

445 DOC respiration occurs in soil porewaters, in groundwater, or in the stream and river network

446 itself. Further study is also needed to evaluate to what extent the controls on aquatic microbial

447 respiration are physiological (Raymond et al. 2016; Catalán et al. 2016) or biochemical (i.e., the

448 chemical nature of DOC inhibits complete metabolism or seasonal changes in water temperature

449 affect bacterial respiration rates). 


\subsection{Placing carbon cycling in the Fraser Basin within a global context}

There is growing recognition that rivers do not simply serve as pipelines that transfer carbon exported from terrestrial landscapes to the ocean, but rather function as reactors where carbon is supplied, processed and remineralized by myriad biological and physicochemical processes during transit from source to sink (Ward et al. 2017). Dissolved organic matter appears to play an important role along the aquatic continuum, both as a major mode of carbon input, but also as a key vector in the cycling of carbon between the biosphere, hydrosphere and atmosphere. In the Fraser Basin, we find a strong coupling between DOC and the portion of DIC that originates from DOC respiration.

The carbon isotopic signatures of Fraser River DOC and DIC are consistent with many large rivers globally (Fig. 7; Marwick et al. 2015), implying that the sources and underlying processes contributing to dissolved carbon carried by the river are representative of many major fluvial systems. In the case of DOC, the Fraser River falls well within the range of values exhibited by rivers globally for $\delta^{13} \mathrm{C}$ composition and ${ }^{14} \mathrm{C}$ age; all of our observed Fraser River $\Delta^{14} \mathrm{C}$-DOC values are near the center of the global distribution (median 46\%; Marwick et al. 2015), with the exception of the relatively aged samples from the Rocky Mountain region, indicating some contribution from deep soil or anthropogenic combustion-derived OM. The range of $\delta^{13} \mathrm{C}$-DIC values in the Fraser River is on the more positive end of the full global range, and roughly in the middle between atmospheric $\mathrm{CO}_{2}$ and carbonate weathering, with some samples trending towards the silicate weathering/organic matter end-members. The ${ }^{14} \mathrm{C}$ composition of Fraser River DIC is average compared to rivers globally, being slightly more aged than modern atmospheric $\mathrm{CO}_{2}$. Together, the ${ }^{13} \mathrm{C}$ and ${ }^{14} \mathrm{C}$ composition of Fraser River DIC support the interpretation of a mixture between weathering of mineral carbonate and modern 
sources such as atmospheric $\mathrm{CO}_{2}$ (precipitation, gas exchange), as well as respiration of biogenic OM. The modest DOC concentrations of the Fraser River and most of its tributaries (mean of the basin-wide dataset in this study $=3 \mathrm{mg} \mathrm{L}^{-1}$ ) and the generally modern $\Delta{ }^{14} \mathrm{C}$-DOC values we observed do not indicate significant anthropogenic disturbance of the river's DOC load. As a consequence of anthropogenic climate change, the Fraser watershed is experiencing rising temperatures (which may mobilize aged OM in mountainous areas) and more severe wildfires (which may deposit a mixture of modern vegetation-derived and aged soil-derived OM on the landscape). Future studies which characterize the impacts of these changes on the age of DOC and DIC in the Fraser River may further elucidate the sources of carbon to these pools and the magnitude of DIC production from OM mineralization.

\section{Conclusions}

The sources of DIC and DOC in the Fraser basin are spatially decoupled, yet their downstream dynamics appear to be intertwined. Carbonate weathering as a source of DIC is pronounced in certain headwater basins (Robson and McGregor rivers), as indicated by high DIC concentrations, relatively low $\Delta{ }^{14} \mathrm{C}-\mathrm{DIC}$ values, and high ratios of dissolved $\mathrm{Ca} / \mathrm{Na}$ and $\mathrm{Mg} / \mathrm{Na}$. Downstream of these basins, tributaries carrying a disproportionately high DOC load (Blackwater, Nechako, and Willow rivers) enter the Fraser. Despite this spatial variability, DIC and DOC concentrations broadly parallel one another along the course of the Fraser main stem. Using a mass balance approach based on major ion ratios and carbon isotope compositions, we estimate that DOC respiration accounts for up to $29 \%$ of the DIC load in some parts of the Fraser basin, while in others the DOC contribution to DIC is insignificant. The Fraser River is an ideal setting for this type of investigation on account of its wide natural variability in lithology and biogeoclimatic zones, and its limited anthropogenic disturbance. To better constrain estimates of 
497 carbon sources and fluxes, future studies would benefit from seasonal sampling and the addition 498 of other carbon pools (particulate organic and inorganic carbon, soil carbonates, groundwater, 499 and hot springs in the Coast Range), as well as simultaneous stable sulfur and oxygen isotope 500 analysis of dissolved sulfate to refine the estimate of sulfuric acid weathering. Estimations of 501 petrogenic carbon weathering fluxes, for instance based on the dissolved rhenium proxy (Hilton 502 et al. 2014), would also help to better constrain the dissolved carbon budget of the Fraser River. 503 Studies like this are important to assess the relative importance of mineral weathering and OC 504 respiration in the terrestrial aquatic continuum, and to predict future carbon cycle changes in 505 aquatic ecosystems in the face of regional and global environmental change. 


\section{Table 1. Dissolved carbon data}

All dissolved organic and inorganic carbon data. Lab ID indicates NOSAMS accession numbers. See Supplementary Information (Table S2) for sample locations and discharge information.

\begin{tabular}{|c|c|c|c|c|c|c|c|c|c|c|c|c|c|}
\hline \multirow{2}{*}{ Site } & \multirow{2}{*}{$\begin{array}{c}\text { Date } \\
\text { (yyyy-mm-dd) }\end{array}$} & \multirow{2}{*}{$\begin{array}{c}\text { DIC } \\
\left(\mu \mathrm{mol} \mathrm{L}{ }^{-1}\right)\end{array}$} & \multirow{2}{*}{$\begin{array}{c}\text { DOC } \\
\left(\mu \mathrm{mol} \mathrm{L}{ }^{-1}\right)\end{array}$} & \multirow{2}{*}{$\begin{array}{l}\text { DIC Flux } \\
\left(\mathrm{mol} \mathrm{s}^{-1}\right) \\
\end{array}$} & \multirow{2}{*}{$\begin{array}{c}\text { DOC Flux } \\
\left(\mathrm{mol} \mathrm{s}^{-1}\right) \\
\end{array}$} & \multicolumn{2}{|c|}{$\delta^{13} \mathrm{C}-\mathrm{DIC}$} & \multicolumn{2}{|c|}{$\delta^{13} \mathrm{C}-\mathrm{DOC}$} & \multicolumn{2}{|c|}{$\Delta^{14} \mathrm{C}$-DIC } & \multicolumn{2}{|c|}{$\Delta^{14} \mathrm{C}-\mathrm{DOC}$} \\
\hline & & & & & & $(\%)$ & Lab ID & $(\%)$ & Lab ID & $(\%)$ & Lab ID & $(\%)$ & Lab ID \\
\hline Fraser at Fitzwilliam & 2010-10-14 & 803 & 117 & 29 & 4.2 & & & & & & & & \\
\hline Fraser at Fitzwilliam & 2009-08-03 & 506 & 44 & 43 & 3.8 & -4.28 & OS-79353 & -26.18 & OS-79924 & -110.4 & OS-79353 & 7.8 & OS-79924 \\
\hline Fraser at Fitzwilliam & 2011-06-03 & 719 & 189 & 77 & 20.2 & & & & & & & & \\
\hline Fraser at McBride & 2010-10-14 & 1106 & 69 & 164 & 10.2 & & & & & & & & \\
\hline Fraser at McBride & 2009-08-04 & 708 & 20 & 321 & 9.3 & & & -26.66 & OS-86824 & & & -77.1 & OS-86824 \\
\hline Fraser at McBride & 2011-06-02 & 891 & 161 & 421 & 76.3 & & & & & & & & \\
\hline Fraser at Hansard & 2010-10-16 & 2012 & 297 & 537 & 79.3 & & & & & & & & \\
\hline Fraser at Hansard & 2009-08-04 & 1103 & 54 & 767 & 37.4 & & & & & & & & \\
\hline Fraser at Hansard & 2011-06-01 & 1065 & 233 & 1513 & 331.5 & & & & & & & & \\
\hline Fraser at Stoner & 2010-10-19 & & 243 & & & & & & & & & & \\
\hline Fraser at Stoner & 2009-08-08 & 981 & 199 & & & -6.73 & OS-79356 & -26.87 & OS-85055 & -145.5 & OS-79356 & 84.8 & OS-85055 \\
\hline Fraser at Lillooet & 2010-10-21 & & 235 & & 214.7 & & & & & & & & \\
\hline Fraser at Lillooet & 2009-08-10 & & 156 & & 329.9 & -6.40 & OS-79360 & -26.69 & OS-80197 & -141.5 & OS-79360 & 73.1 & OS-80197 \\
\hline Fraser at Lillooet & 2011-05-28 & 1077 & 642 & 6636 & 3957.1 & & & -27.49 & OS-149273 & & & 47.3 & OS-149273 \\
\hline Fraser at Lytton & $2010-10-22$ & & 205 & & & & & & & & & & \\
\hline Fraser at Lytton & 2009-08-01 & 953 & 145 & & & & & & & & & & \\
\hline Fraser at Hope & $2010-10-24$ & & 216 & & 406.4 & & & & & & & & \\
\hline Fraser at Hope & $2011-05-27$ & 797 & 418 & 7004 & 3674.8 & & & & & & & & \\
\hline Fraser at Fort Langley & $2010-10-25$ & 1015 & 193 & 2222 & 423.0 & & & & & & & & \\
\hline Fraser at Fort Langley & 2009-07-30 & 824 & & 3870 & & -6.26 & OS-79351 & & & -118.7 & OS-79351 & & \\
\hline Fraser at Fort Langley & 2009-08-13 & 798 & 131 & 2725 & 448.5 & & & -26.67 & OS-85364 & & & 58.6 & OS-85364 \\
\hline Fraser at Fort Langley & 2011-06-07 & 893 & 386 & 9039 & 3903.6 & & & & & & & & \\
\hline Fraser at Vancouver shallow & $2009-07-28$ & 660 & 130 & 3018 & 594.5 & -6.49 & OS-79349 & -26.82 & OS-79920 & -124.7 & OS-79349 & 45.1 & OS-79920 \\
\hline Fraser at Vancouver deep & $2009-07-28$ & 672 & 132 & 3072 & 601.3 & -6.62 & OS-79350 & & & -129.1 & OS-79350 & & \\
\hline Robson River & 2010-10-14 & 1416 & 31 & & & & & & & & & & \\
\hline Robson River & $2009-08-03$ & 1211 & 17 & & & -4.57 & OS-79354 & -26.82 & OS-85391 & -294.3 & OS-79354 & -61.4 & OS-85391 \\
\hline
\end{tabular}




\begin{tabular}{|c|c|c|c|c|c|c|c|c|c|c|c|c|c|}
\hline Bowron River & 2009-08-05 & 1561 & 108 & 39 & 2.7 & & & & & & & & \\
\hline Bowron River & 2011-05-31 & 1083 & 365 & 328 & 110.7 & & & & & & & & \\
\hline McGregor River & 2010-10-16 & 1671 & 177 & 204 & 21.6 & & & & & & & & \\
\hline McGregor River & 2009-08-05 & 1366 & 27 & 287 & 5.7 & & & -27.02 & OS-86823 & & & -80.2 & OS-86823 \\
\hline McGregor River & 2011-06-01 & 1126 & 211 & 772 & 145.1 & & & & & & & & \\
\hline Willow River & 2010-10-15 & 1042 & 289 & 11 & 3.1 & & & & & & & & \\
\hline Willow River & 2009-08-06 & 1185 & 276 & 9 & 2.1 & & & & & & & & \\
\hline Willow River & 2011-05-31 & 536 & 694 & 124 & 160.4 & & & & & & & & \\
\hline Nechako River & 2010-10-17 & 1124 & 437 & 120 & 46.8 & & & & & & & & \\
\hline Nechako River & 2009-08-06 & 737 & 395 & 417 & 223.8 & -6.38 & OS-79355 & -27.32 & OS-79938 & -3.8 & OS-79355 & 82.5 & OS-79938 \\
\hline Nechako River & 2011-05-31 & 868 & 850 & 650 & 635.9 & & & & & & & & \\
\hline Stuart Lake & 2009-08-07 & 885 & 488 & 215 & 118.6 & & & & & & & & \\
\hline Blackwater River & 2010-10-18 & 1553 & 466 & 38 & 11.3 & & & & & & & & \\
\hline Blackwater River & 2009-08-08 & 1631 & 546 & 36 & 12.2 & -8.74 & OS-79357 & -26.50 & OS-80079 & -56.4 & OS-79357 & 55.5 & OS-80079 \\
\hline Blackwater River & 2011-05-30 & 986 & 1479 & 410 & 615.2 & & & -27.12 & OS-149272 & & & 74.3 & OS-149272 \\
\hline Quesnel River & 2010-10-19 & 1061 & 124 & 134 & 15.7 & & & & & & & & \\
\hline Quesnel River & 2009-08-09 & 983 & 88 & 271 & 24.3 & -4.73 & OS-79358 & -26.36 & OS-85370 & -135.4 & OS-79358 & 52.0 & OS-85370 \\
\hline Quesnel River & 2011-05-30 & 1125 & 268 & 931 & 221.7 & & & & & & & & \\
\hline Chilcotin River & 2010-10-20 & 733 & 90 & 72 & 8.8 & & & & & & & & \\
\hline Chilcotin River & 2009-08-09 & 518 & 83 & 130 & 20.9 & -3.80 & OS-79359 & -26.20 & OS-85385 & -26.1 & OS-79359 & 11.7 & OS-85385 \\
\hline Chilcotin River & 2011-05-29 & 1396 & 1055 & 302 & 227.9 & & & -27.05 & OS-149271 & & & 70.2 & OS-149271 \\
\hline Bridge River & 2010-10-21 & 1684 & 70 & & & & & & & & & & \\
\hline Bridge River & 2009-08-10 & & 49 & & & & & & & & & & \\
\hline Bridge River & 2011-05-28 & & 205 & & & & & & & & & & \\
\hline Thompson River & $2010-10-22$ & 733 & 172 & 315 & 73.8 & & & & & & & & \\
\hline Thompson River & 2009-08-01 & 598 & 115 & 578 & 111.6 & -5.36 & OS-79352 & -26.55 & OS-79921 & -71.5 & OS-79352 & 55.5 & OS-79921 \\
\hline Thompson River & 2011-05-27 & 812 & 414 & 1915 & 976.8 & & & & & & & & \\
\hline Harrison River & 2010-10-24 & 397 & 127 & 114 & 36.4 & & & & & & & & \\
\hline Harrison River & 2009-07-31 & 295 & 74 & 197 & 49.5 & & & -26.38 & OS-84841 & & & 16.2 & OS-84841 \\
\hline Harrison River & 2011-05-26 & 343 & 115 & 196 & 65.6 & & & & & & & & \\
\hline Pitt River & $2010-10-25$ & & 118 & & & & & & & & & & \\
\hline Pitt River & 2011-05-26 & 140 & 139 & & & & & & & & & & \\
\hline
\end{tabular}


Table 2. DOC time series

DOC concentrations, fluxes and $\Delta{ }^{14} \mathrm{C}$ values throughout 2013 near the mouth of the Fraser River (at Fort Langley). Lab ID indicates ETH sample numbers.

\begin{tabular}{lccccc}
\hline Date & DOC & DOC Flux & $\Delta^{14} \mathrm{C}$ & $\Delta^{14} \mathrm{C}$ error & Lab ID \\
$($ yyyy-mm-dd $)$ & $\left(\mu \mathrm{mol} \mathrm{L}^{-1}\right)$ & $\left(\mathrm{mol} \mathrm{C} \mathrm{s}^{-1}\right)$ & $(\%)$ & $(\%)$ & \\
\hline $2013-01-12$ & 257 & 273 & -65.0 & 21.9 & 56995.1 .1 \\
$2013-02-09$ & 248 & 248 & -26.1 & 23.7 & 56997.1 .1 \\
$2013-02-09$ & 248 & 248 & 1.5 & 28.8 & 56998.1 .1 \\
$2013-03-16$ & 242 & 349 & -49.9 & 23.8 & 56999.1 .1 \\
$2013-03-30$ & 205 & 270 & -9.9 & 29.5 & 56987.1 .1 \\
$2013-03-30$ & 205 & 270 & 31.5 & 35.3 & 56988.1 .1 \\
$2013-04-07$ & 266 & 608 & 2.8 & 22.1 & 56989.1 .1 \\
$2013-04-10$ & 415 & 1132 & 24.1 & 17.5 & 56991.1 .1 \\
$2013-04-16$ & 558 & 1599 & 24.8 & 13.3 & 56993.1 .1 \\
$2013-05-01$ & 760 & 3480 & -29.5 & 10.5 & 57001.1 .1 \\
$2013-05-17$ & 389 & 4322 & 28.9 & 17.3 & 57003.1 .1 \\
$2013-06-22$ & 226 & 1938 & 5.0 & 26.5 & 57005.1 .1 \\
$2013-07-24$ & 184 & 840 & 14.2 & 31.1 & 57007.1 .1 \\
$2013-07-24$ & 184 & 840 & -25.7 & 31.6 & 57008.1 .1 \\
$2013-09-20$ & 130 & 319 & -2.7 & 38.3 & 57009.1 .1 \\
$2013-10-25$ & & & -106.1 & 30.6 & 57011.1 .1 \\
$2013-11-15$ & & & 21.1 & 34.8 & 57013.1 .1 \\
$2013-12-19$ & & & -68.7 & 31.4 & 57015.1 .1 \\
\hline
\end{tabular}


Table 3. DIC time series

DIC concentrations and fluxes near the mouth of the Fraser River (at Fort Langley).

\begin{tabular}{lcc}
\hline $\begin{array}{l}\text { Date } \\
\text { (yyyy-mm-dd })\end{array}$ & $\begin{array}{c}\text { DIC } \\
\left(\mu \mathrm{mol} \mathrm{L}^{-1}\right)\end{array}$ & $\begin{array}{c}\text { DIC Flux } \\
\left(\mathrm{mol} \mathrm{C} \mathrm{s}^{-1}\right)\end{array}$ \\
\hline $2009-07-30$ & 824 & 3870 \\
$2009-08-13$ & 798 & 2725 \\
$2010-10-25$ & 1015 & 2222 \\
$2011-05-25$ & 913 & 7841 \\
$2011-06-07$ & 893 & 9351 \\
$2011-06-26$ & 800 & 7886 \\
$2011-06-28$ & 794 & 7955 \\
$2011-07-08$ & 770 & 7458 \\
$2011-07-15$ & 877 & 8553 \\
$2011-07-19$ & 839 & 8098 \\
$2011-10-14$ & 782 & 2124 \\
$2011-10-25$ & 892 & 2012 \\
$2011-10-26$ & 864 & 1931 \\
$2011-10-31$ & 900 & 1940 \\
$2011-11-15$ & 1011 & 1972 \\
$2011-12-12$ & 1003 & 1281 \\
$2012-01-11$ & 937 & 1646 \\
$2012-02-10$ & 1073 & 1300 \\
$2012-07-05$ & 798 & 8308 \\
$2012-07-13$ & 765 & 7425 \\
\hline
\end{tabular}




\section{Table 4. Estimates of DIC derived from DOC respiration}

The portion of DIC derived from DOC respiration, expressed as a concentration ([DIC $]_{\text {DOC }}$ ) and as a fraction of total DIC ( $f_{D O C}$ ), demonstrates that DOC respiration can constitute a significant portion of the total DIC load.

\begin{tabular}{lcc}
\hline Site & $\begin{array}{c}{[\mathrm{DIC}]_{\mathrm{DOC}}} \\
\left(\mu \mathrm{mol} \mathrm{L}{ }^{-1}\right)\end{array}$ & $\mathrm{f}_{\mathrm{DOC}}$ \\
\hline Fraser at Fitzwilliam & 3 & 0.01 \\
Fraser at Stoner & 282 & 0.29 \\
Fraser at Vancouver shallow & 106 & 0.16 \\
Nechako River & 141 & 0.19 \\
Blackwater River & 427 & 0.26 \\
Quesnel River & 207 & 0.21 \\
Chilcotin River & 21 & 0.04 \\
Thompson River & 95 & 0.16 \\
\hline
\end{tabular}




\section{Figure captions}

Fig. 1 Map of the Fraser River Basin and major tributaries sampled in this study. Inset map indicates the location of the Fraser River Basin in North America. "F" before a station name indicates locations on the Fraser main stem. Time series samples (Table 2) were collected at the Fraser at Fort Langley station.

Fig. 2 Concentrations ( $\mu \mathrm{mol} \mathrm{L} \mathrm{L}^{-1}$ ) of DIC (panels A-C) and DOC (panels D-F) across the Fraser basin at low discharge (left panels), medium discharge (center panels), and high discharge (right panels).

Fig. 3 DIC and DOC fluxes $\left(\mathrm{mol} \mathrm{s}^{-1}\right)$ in tributaries of the Fraser River under low, medium, and high discharge conditions. Note the difference in scale of the axes.

Fig. 4 Isotope compositions (\%o) of Fraser basin dissolved carbon pools in summer 2009: $\delta^{13} \mathrm{C}$ of DIC (A) and DOC (B) and $\Delta^{14} \mathrm{C}$ of DIC (C) and DOC (D).

Fig. 5 The 2013 time series record of (A) DOC concentration and (B) DOC flux exhibit a pronounced pulse in the early stages of the spring freshet followed by a rapid decay. In contrast, the $\Delta^{14} \mathrm{C}$-DOC during this period (C) is relatively constant and nearly modern throughout the year.

Fig. 6 The correlation between the estimated contribution of DOC respiration to the DIC load $\left(\mathrm{DIC}_{\mathrm{DOC}} ; \mathrm{r}^{2}=0.58\right)$ supports the isotope mass balance approach to this calculation.

Fig. 7 Radiocarbon $\left(\Delta^{14} \mathrm{C}, \%\right)$ and stable carbon isotope $\left(\delta^{13} \mathrm{C}, \%\right)$ compositions of DOC and DIC in the Fraser River in the context of global river variability (after Marwick et al. 2015). Hypothetical end-members are shown both in their natural form (dashed outlines) and as " $\mathrm{HCO}_{3}$ " equivalents" (solid outlines and * labels) accounting for a fractionation effect between $\mathrm{CO}_{2}(g)$ and $\mathrm{HCO}_{3}{ }^{-}(a q)$ of $9.6 \%$, assuming a temperature of $10^{\circ} \mathrm{C}$ (Clark and Fritz 1997). 


\section{References}

Aufdenkampe AK, Mayorga E, Raymond PA, et al (2011) Riverine coupling of biogeochemical cycles between land, oceans, and atmosphere. Frontiers in Ecology and the Environment 9:53-60. https://doi.org/10.1890/100014

Battin TJ, Luyssaert S, Kaplan LA, et al (2009) The boundless carbon cycle. Nature Geosci 2:598-600. https://doi.org/10.1038/ngeo618

Beaupré SR, Druffel ERM, Griffin S (2007) A low-blank photochemical extraction system for concentration and isotopic analyses of marine dissolved organic carbon: Marine DOC concentration and isotope ratios. Limnol Oceanogr Methods 5:174-184. https://doi.org/10.4319/lom.2007.5.174

Blattmann TM, Wang S-L, Lupker M, et al (2019) Sulphuric acid-mediated weathering on Taiwan buffers geological atmospheric carbon sinks. Sci Rep 9:2945. https://doi.org/10.1038/s41598-019-39272-5

Burke A, Present TM, Paris G, et al (2018) Sulfur isotopes in rivers: Insights into global weathering budgets, pyrite oxidation, and the modern sulfur cycle. Earth and Planetary Science Letters 496:168-177. https://doi.org/10.1016/j.epsl.2018.05.022

Butman D, Raymond PA (2011) Significant efflux of carbon dioxide from streams and rivers in the United States. Nature Geosci 4:839-842. https://doi.org/10.1038/ngeo1294

Butman D, Stackpoole S, Stets E, et al (2016) Aquatic carbon cycling in the conterminous United States and implications for terrestrial carbon accounting. Proc Natl Acad Sci USA 113:58-63. https://doi.org/10.1073/pnas.1512651112

Cai W-J (2011) Estuarine and Coastal Ocean Carbon Paradox: $\mathrm{CO}_{2}$ Sinks or Sites of Terrestrial Carbon Incineration? Annu Rev Mar Sci 3:123-145. https://doi.org/10.1146/annurevmarine-120709-142723

Calmels D, Gaillardet J, Brenot A, France-Lanord C (2007) Sustained sulfide oxidation by physical erosion processes in the Mackenzie River basin: Climatic perspectives. Geol 35:1003. https://doi.org/10.1130/G24132A.1

Cameron EM (1996) Hydrogeochemistry of the Fraser River, British Columbia: seasonal variation in major and minor components. Journal of Hydrology 182:209-225

Cameron EM, Hall GEM, Veizer J, Krouse HR (1995) Isotopic and elemental hydrogeochemistry of a major river system: Fraser River, British Columbia, Canada. Chemical Geology 122:149-169

Cameron EM, Hattori K (1997) Strontium and neodymium isotope ratios in the Fraser River: a riverine transect across the Cordilleran orogen. Chemical Geology 137:243-253 
Catalán N, Marcé R, Kothawala DN, Tranvik LarsJ (2016) Organic carbon decomposition rates controlled by water retention time across inland waters. Nature Geosci 9:501-504. https://doi.org/10.1038/ngeo2720

Clark ID, Fritz P (1997) Tracing the Carbon Cycle. In: Environmental Isotopes in Hydrogeology. CRC Press, pp 111-136

Cole JJ, Caraco NF (2001) Carbon in catchments: connecting terrestrial carbon losses with aquatic metabolism. Marine and Freshwater Research 52:101-110

Cooper LW, McClelland JW, Holmes RM, et al (2008) Flow-weighted values of runoff tracers $\delta 180$, DOC, Ba, alkalinity) from the six largest Arctic rivers. Geophys Res Lett 35:L18606. https://doi.org/10.1029/2008GL035007

Coppola AI, Wiedemeier DB, Galy V, et al (2018) Global-scale evidence for the refractory nature of riverine black carbon. Nature Geosci 11:584-588. https://doi.org/10.1038/s41561-018-0159-8

Dickson A (2010) Standards for Ocean Measurements. Oceanog 23:34-47. https://doi.org/10.5670/oceanog.2010.22

Eglinton TI, Repeta DJ (2014) Organic Matter in the Contemporary Ocean. In: Treatise on Geochemistry, edited by H. Holland and K. Turekian. Elsevier, pp 151-189

Gaillardet J, Dupré B, Louvat P, Allègre CJ (1999) Global silicate weathering and CO2 consumption rates deduced from the chemistry of large rivers. Chemical Geology 159:330

Galy V, Peucker-Ehrenbrink B, Eglinton T (2015) Global carbon export from the terrestrial biosphere controlled by erosion. Nature 521:204-207. https://doi.org/10.1038/nature14400

Guo L, Cai Y, Belzile C, Macdonald RW (2012) Sources and export fluxes of inorganic and organic carbon and nutrient species from the seasonally ice-covered Yukon River. Biogeochemistry 107:187-206. https://doi.org/10.1007/s10533-010-9545-z

Hallett DJ, Lepofsky DS, Mathewes RW, Lertzman KP (2003) 11000 years of fire history and climate in the mountain hemlock rain forests of southwestern British Columbia based on sedimentary charcoal. Can J For Res 33:292-312. https://doi.org/10.1139/x02-177

Hedges JI, Keil RG, Benner R (1997) What happens to terrestrial organic matter in the ocean? Organic Geochemistry 27:195-212. https://doi.org/10.1016/S0146-6380(97)00066-1

Hemingway JD, Olson H, Turchyn AV, et al (2020) Triple oxygen isotope insight into terrestrial pyrite oxidation. Proc Natl Acad Sci USA 117:7650-7657. https://doi.org/10.1073/pnas.1917518117 
Hemingway JD, Spencer RGM, Podgorski DC, et al (2019) Glacier meltwater and monsoon precipitation drive Upper Ganges Basin dissolved organic matter composition. Geochimica et Cosmochimica Acta 244:216-228. https://doi.org/10.1016/j.gca.2018.10.012

Hilton RG, Gaillardet J, Calmels D, Birck J-L (2014) Geological respiration of a mountain belt revealed by the trace element rhenium. Earth and Planetary Science Letters 403:27-36. https://doi.org/10.1016/j.epsl.2014.06.021

Hilton RG, West AJ (2020) Mountains, erosion and the carbon cycle. Nat Rev Earth Environ 1:284-299. https://doi.org/10.1038/s43017-020-0058-6

Holmes RM, McClelland JW, Raymond PA, et al (2008) Lability of DOC transported by Alaskan rivers to the Arctic Ocean. Geophys Res Lett 35:L03402. https://doi.org/10.1029/2007GL032837

Hood E, Fellman J, Spencer RGM, et al (2009) Glaciers as a source of ancient and labile organic matter to the marine environment. Nature 462:1044-1047. https://doi.org/10.1038/nature08580

Jaffé R, Ding Y, Niggemann J, et al (2013) Global Charcoal Mobilization from Soils via Dissolution and Riverine Transport to the Oceans. Science 340:345-347. https://doi.org/10.1126/science.1231476

Lang SQ, McIntyre CP, Bernasconi SM, et al (2016) Rapid 14C Analysis of Dissolved Organic Carbon in Non-Saline Waters. Radiocarbon 58:505-515. https://doi.org/10.1017/RDC.2016.17

Marwick TR, Tamooh F, Teodoru CR, et al (2015) The age of river-transported carbon: A global perspective: The age of river-transported carbon. Global Biogeochem Cycles 29:122137. https://doi.org/10.1002/2014GB004911

McNichol AP, Schneider RJ, von Reden KF, et al (2000) Ten years after - The WOCE AMS radiocarbon program. Nuclear Instruments and Methods in Physics Research Section B: Beam Interactions with Materials and Atoms 172:479-484. https://doi.org/10.1016/S0168-583X(00)00093-8

Meybeck M (1986) Composition chimique des ruisseaux non pollués de France. Sciences Géologiques, Bulletin 39:3-77

Négrel P, Allègre CJ, Dupré B, Lewin E (1993) Erosion sources determined by inversion of major and trace element ratios and strontium isotopic ratios in river water: The Congo Basin case. Earth and Planetary Science Letters 120:59-76. https://doi.org/10.1016/0012821X(93)90023-3

Perdue EM, Beck KC, Reuter JH (1976) Organic complexes of iron and aluminium in natural waters. Nature 260:418-420 
Raymond PA, Hartmann J, Lauerwald R, et al (2013) Global carbon dioxide emissions from inland waters. Nature 503:355-359. https://doi.org/10.1038/nature12760

Raymond PA, Saiers JE, Sobczak WV (2016) Hydrological and biogeochemical controls on watershed dissolved organic matter transport: pulse-shunt concept. Ecology 97:5-16. https://doi.org/10.1890/14-1684.1

Reiman J, Xu Y (2018) Diel Variability of pCO2 and CO2 Outgassing from the Lower Mississippi River: Implications for Riverine CO2 Outgassing Estimation. Water 11:43. https://doi.org/10.3390/w11010043

Roberts ML, Burton JR, Elder KL, et al (2010) A High-Performance 14C Accelerator Mass Spectrometry System. Radiocarbon 52:228-235. https://doi.org/10.1017/S0033822200045252

Sarma VVSS, Kumar NA, Prasad VR, et al (2011) High CO2 emissions from the tropical Godavari estuary (India) associated with monsoon river discharges. Geophys Res Lett 38:. https://doi.org/10.1029/2011GL046928

Schädel C, Bader MK-F, Schuur EAG, et al (2016) Potential carbon emissions dominated by carbon dioxide from thawed permafrost soils. Nature Clim Change 6:950-953. https://doi.org/10.1038/nclimate3054

Spence J, Telmer K (2005) The role of sulfur in chemical weathering and atmospheric CO2 fluxes: Evidence from major ions, $\delta 13 \mathrm{CDIC}$, and $\delta 34 \mathrm{SSO} 4$ in rivers of the Canadian Cordillera. Geochimica et Cosmochimica Acta 69:5441-5458. https://doi.org/10.1016/j.gca.2005.07.011

Stubbins A, Hood E, Raymond PA, et al (2012) Anthropogenic aerosols as a source of ancient dissolved organic matter in glaciers. Nature Geosci 5:198-201. https://doi.org/10.1038/ngeo1403

Thorne R, Woo M (2011) Streamflow response to climatic variability in a complex mountainous environment: Fraser River Basin, British Columbia, Canada. Hydrol Process. https://doi.org/10.1002/hyp.8225

Torres MA, West AJ, Clark KE, et al (2016) The acid and alkalinity budgets of weathering in the Andes-Amazon system: Insights into the erosional control of global biogeochemical cycles. Earth and Planetary Science Letters 450:381-391. https://doi.org/10.1016/j.eps1.2016.06.012

Tranvik LJ, Downing JA, Cotner JB, et al (2009) Lakes and reservoirs as regulators of carbon cycling and climate. Limnol Oceanogr 54:2298-2314. https://doi.org/10.4319/lo.2009.54.6_part_2.2298

Trumbore S (2000) Age of soil organic matter and soil respiration: radiocarbon constraints on belowground $\mathrm{C}$ dynamics 
Voss BM, Peucker-Ehrenbrink B, Eglinton TI, et al (2015) Seasonal hydrology drives rapid shifts in the flux and composition of dissolved and particulate organic carbon and major and trace ions in the Fraser River, Canada. Biogeosciences 12:5597-5618. https://doi.org/10.5194/bg-12-5597-2015

Voss BM, Peucker-Ehrenbrink B, Eglinton TI, et al (2014) Tracing river chemistry in space and time: Dissolved inorganic constituents of the Fraser River, Canada. Geochimica et Cosmochimica Acta 124:283-308. https://doi.org/10.1016/j.gca.2013.09.006

Voss BM, Wickland KP, Aiken GR, Striegl RG (2017) Biological and land use controls on the isotopic composition of aquatic carbon in the Upper Mississippi River Basin. Global Biogeochem Cycles 31:1271-1288. https://doi.org/10.1002/2017GB005699

Wagner S, Coppola AI, Stubbins A, et al (2021) Questions remain about the biolability of dissolved black carbon along the combustion continuum. Nat Commun 12:4281. https://doi.org/10.1038/s41467-021-24477-y

Wang ZA, Lawson GL, Pilskaln CH, Maas AE (2017) Seasonal controls of aragonite saturation states in the Gulf of Maine. J Geophys Res Oceans 122:372-389. https://doi.org/10.1002/2016JC012373

Ward ND, Bianchi TS, Medeiros PM, et al (2017) Where Carbon Goes When Water Flows: Carbon Cycling across the Aquatic Continuum. Front Mar Sci 4:. https://doi.org/10.3389/fmars.2017.00007

Wheeler JO, Brookfield AJ, Gabrielese H, et al (1991) Terrane map of the Canadian Cordillera; Geological Survey of Canada, Map 1713A, scale 1:200,000.

Xu L, Roberts ML, Elder KL, et al (2021) Radiocarbon in dissolved organic carbon by UV oxidation: Procedures and blank characterization at NOSAMS. Radiocarbon 63:357-374. https://doi.org/10.1017/RDC.2020.102 


\section{Statements and Declarations}

\section{Funding}

This work was supported by the WHOI Academic Programs Office, the MIT EAPS Department Student Assistance Fund, and the PAOC Houghton Fund to BMV, NSF-ETBC grants OCE0851015 to BPE, VG, and TIE, and OCE-0851101 to RGMS, NSF grant EAR-1226818 to BPE, NSF grant OCE-0928582 to TIE and VG, and a WHOI Arctic Research Initiative grant to ZAW.

\section{Competing Interests}

The authors have no relevant financial or non-financial interests to disclose.

\section{Author Contributions}

Britta Voss, Timothy Eglinton, Bernhard Peucker-Ehrenbrink, and Valier Galy contributed to the study conception and design and material preparation. The first draft of the manuscript was written by Britta Voss. All authors contributed to data collection and analysis, commented on previous versions of the manuscript, and read and approved the final manuscript.

\section{Data Availability}

All data generated or analyzed during this study are included in this published article and its supplementary information file. Additionally, sample metadata are available in the System for Earth Sample Registration (SESAR) database at www.geosamples.org. See Table S2 for sample codes. 


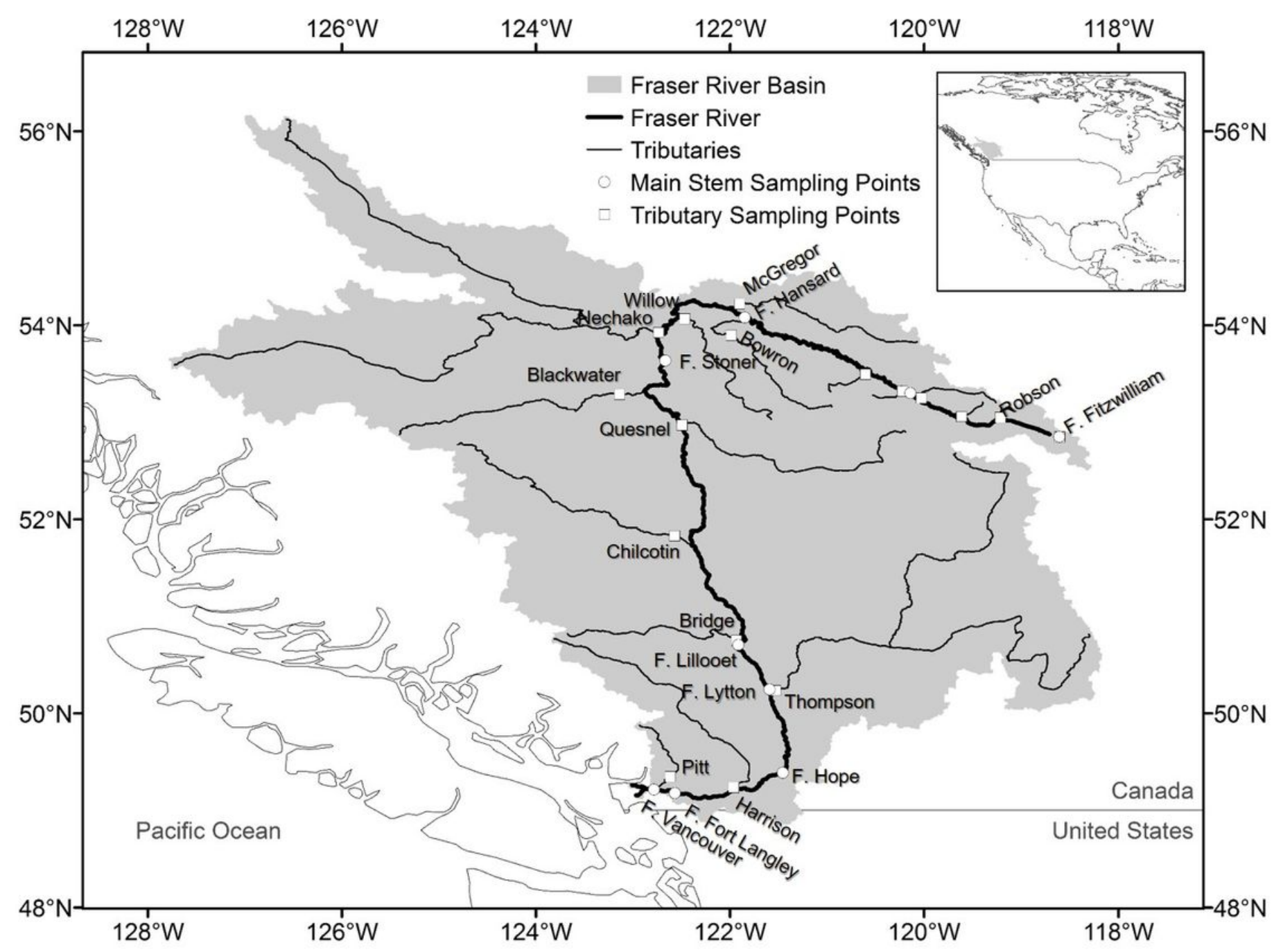

\section{Figure 1}

Map of the Fraser River Basin and major tributaries sampled in this study. Inset map indicates the location of the Fraser River Basin in North America. "F" before a station name indicates locations on the Fraser main stem. Time series samples (Table 2) were collected at the Fraser at Fort Langley station. 

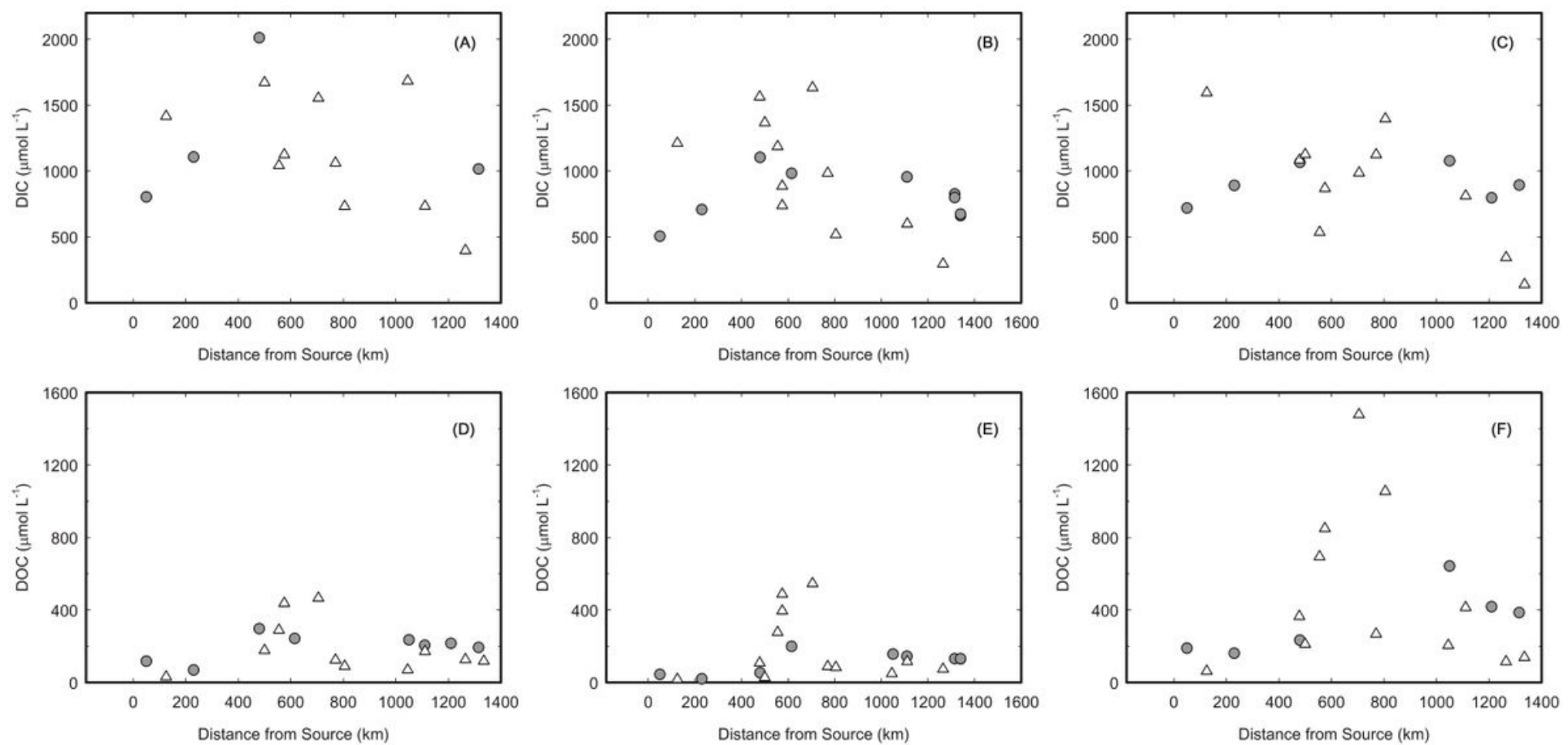

Fraser main stem

$\Delta$ Tributaries

Figure 2

Concentrations ( $\mathrm{mmol} \mathrm{L}^{-1}$ ) of DIC (panels A-C) and DOC (panels D-F) across the Fraser basin at low discharge (left panels), medium discharge (center panels), and high discharge (right panels).
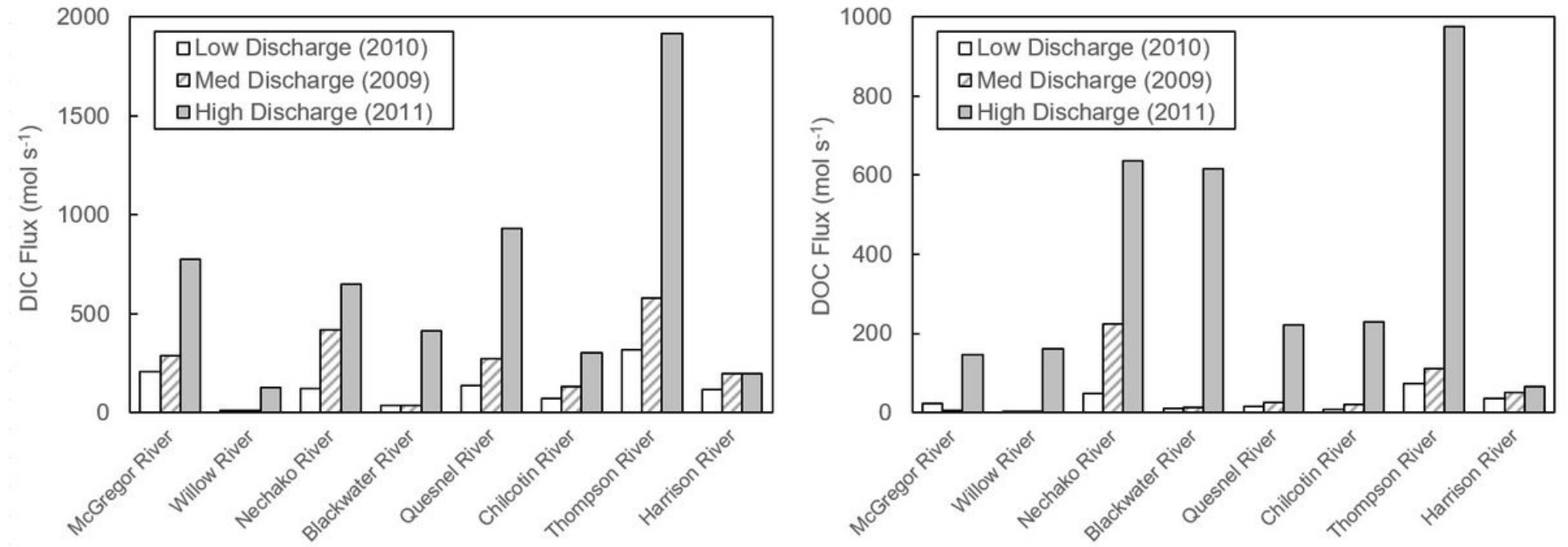

Figure 3

DIC and DOC fluxes $\left(\mathrm{mol} \mathrm{s}^{-1}\right)$ in tributaries of the Fraser River under low, medium, and high discharge conditions. Note the difference in scale of the axes. 

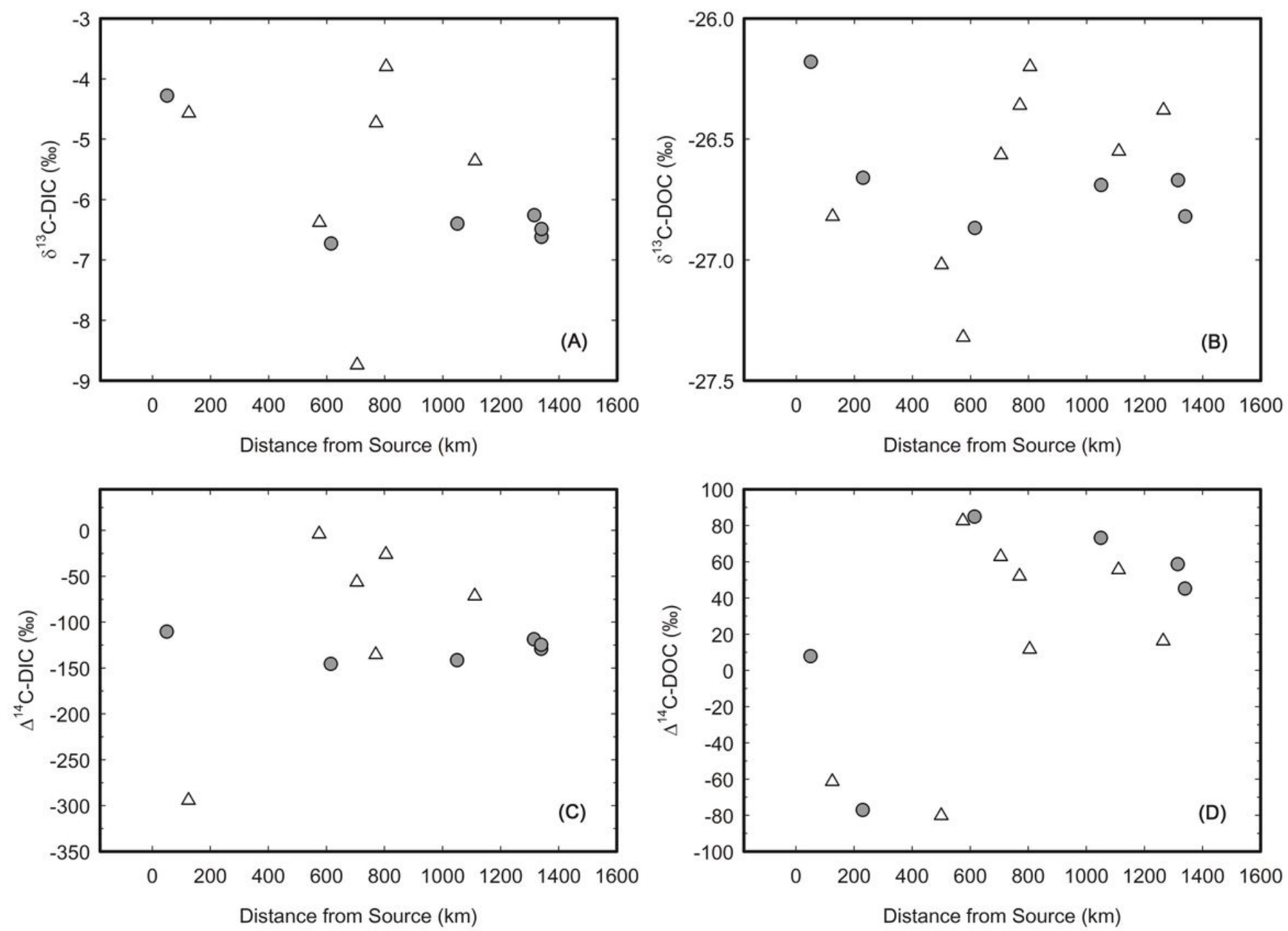

Fraser main stem

$\triangle$ Tributaries

Figure 4

Isotope compositions (\%) of Fraser basin dissolved carbon pools in summer 2009: $\delta^{13} \mathrm{C}$ of DIC (A) and DOC (B) and $\triangle^{14} C$ of DIC (C) and DOC (D). 

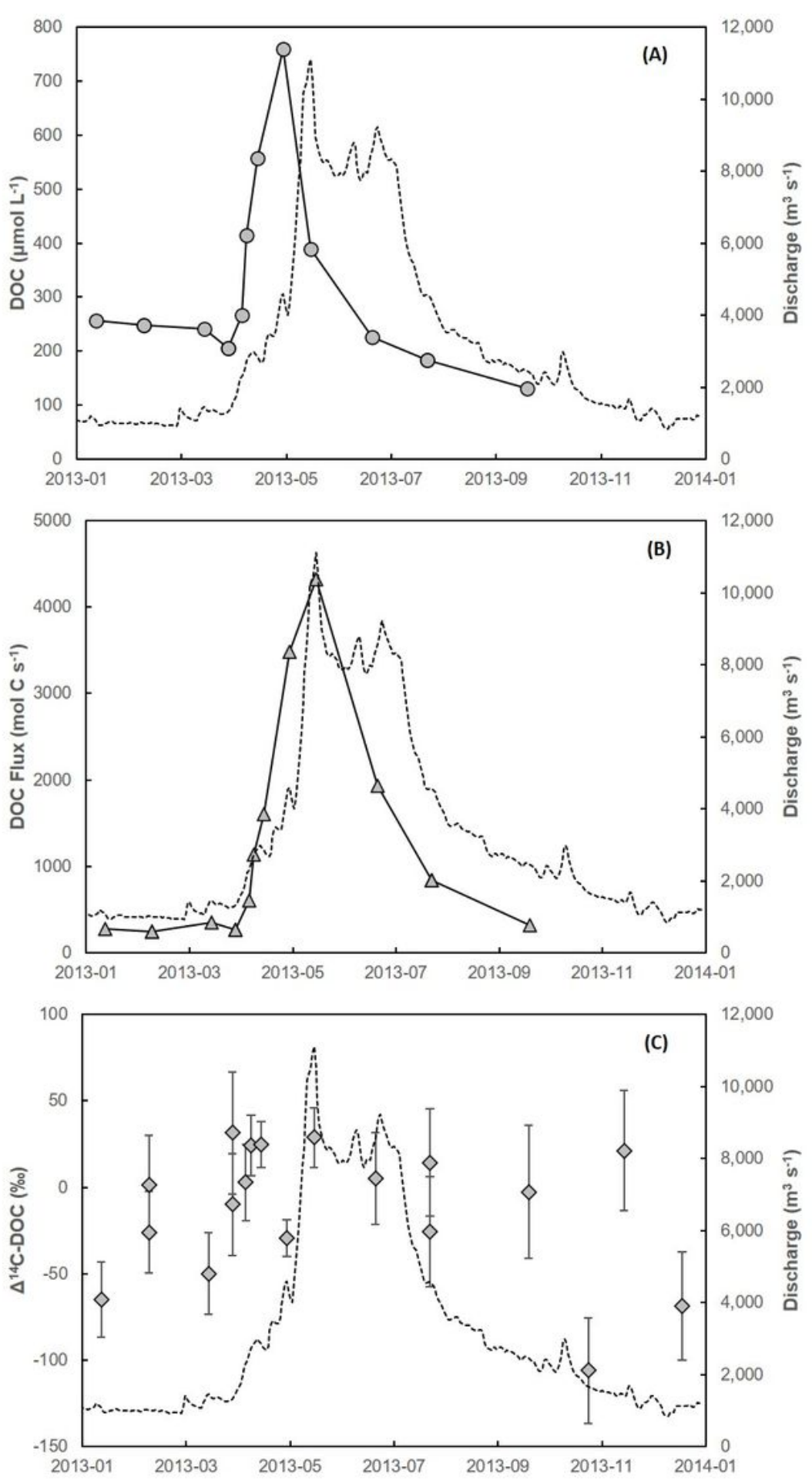

\section{Figure 5}

The 2013 time series record of (A) DOC concentration and (B) DOC flux exhibit a pronounced pulse in the early stages of the spring freshet followed by a rapid decay. In contrast, the $\triangle^{14} \mathrm{C}$-DOC during this period (C) is relatively constant and nearly modern throughout the year. 


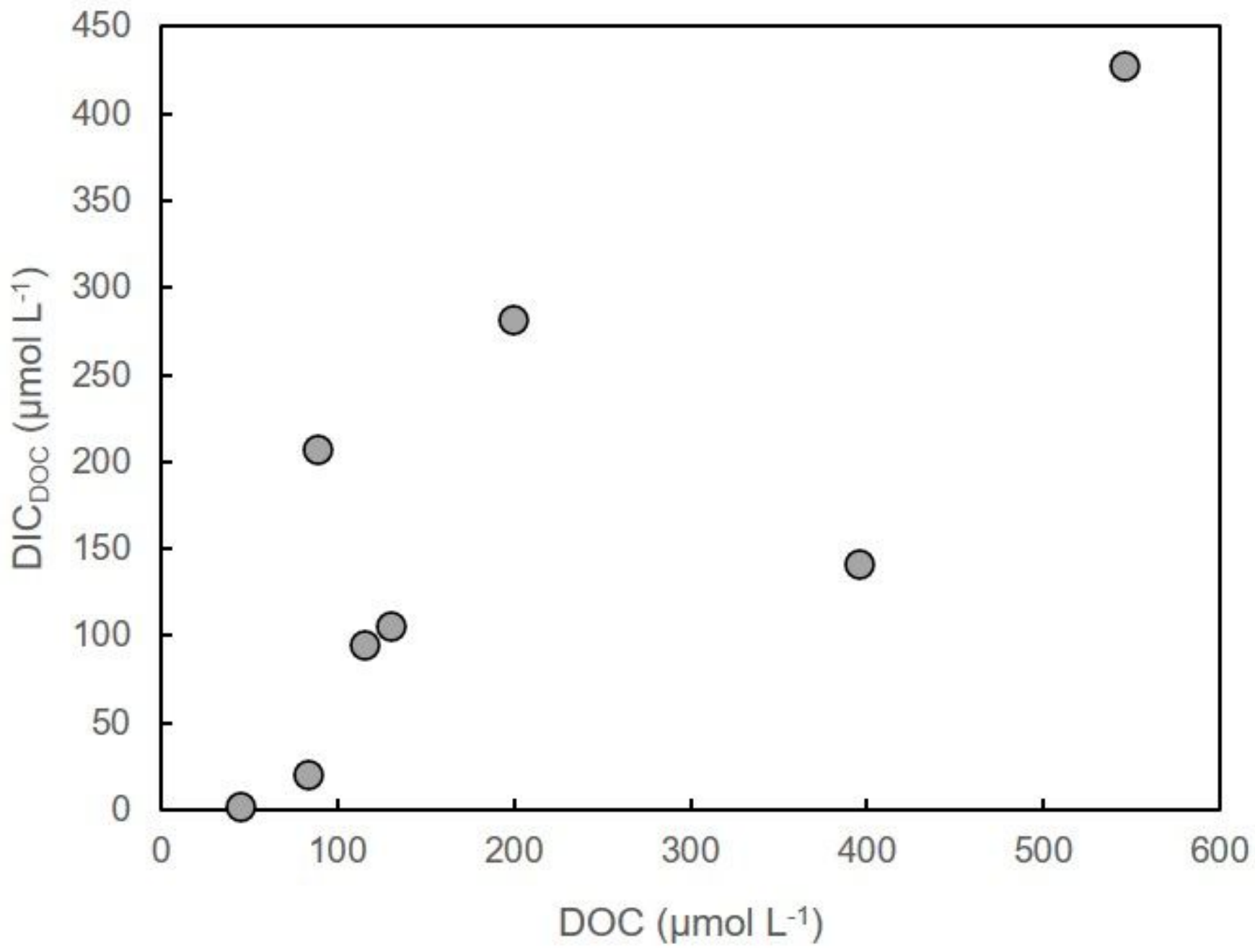

Figure 6

The correlation between the estimated contribution of DOC respiration to the DIC load $\left(\mathrm{DIC}_{\mathrm{DOC}} ; \mathrm{r}^{2}=0.58\right)$ supports the isotope mass balance approach to this calculation. 


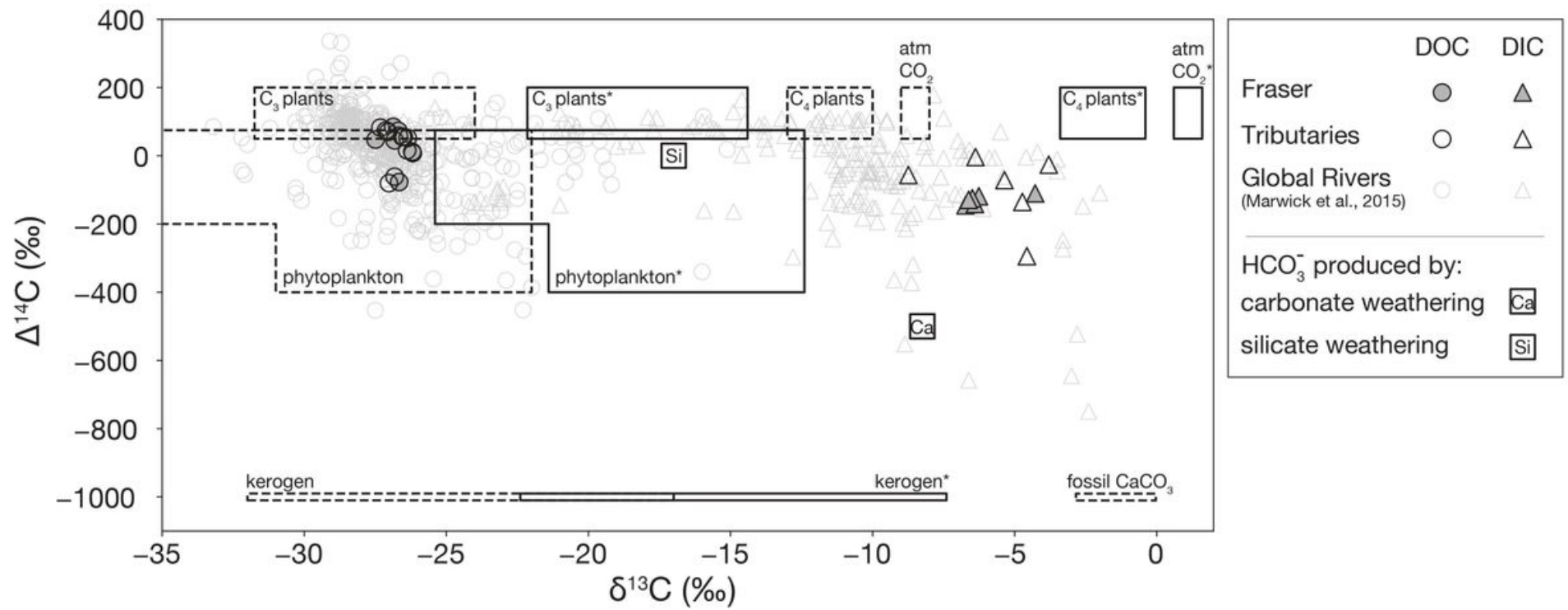

Figure 7

Radiocarbon $\left(D^{14} \mathrm{C}, \% 0\right)$ and stable carbon isotope $\left(\delta^{13} \mathrm{C}, \% 0\right)$ compositions of DOC and DIC in the Fraser River in the context of global river variability (after Marwick et al. 2015). Hypothetical end-members are shown both in their natural form (dashed outlines) and as " $\mathrm{HCO}_{3}{ }^{-}$equivalents" (solid outlines and * labels) accounting for a fractionation effect between $\mathrm{CO}_{2}(\mathrm{~g})$ and $\mathrm{HCO}_{3}{ }^{-}(\mathrm{aq})$ of $9.6 \%$, assuming a temperature of $10^{\circ} \mathrm{C}$ (Clark and Fritz 1997).

\section{Supplementary Files}

This is a list of supplementary files associated with this preprint. Click to download.

- Supplementarylnformation.pdf 